NBER WORKING PAPER SERIES

\title{
RETHINKING THE GAINS FROM IMMIGRATION: THEORY AND \\ EVIDENCE FROM THE U.S.
}

\author{
Gianmarco I.P. Ottaviano \\ Giovanni Peri \\ Working Paper 11672 \\ http://www.nber.org/papers/w11672
}

\author{
NATIONAL BUREAU OF ECONOMIC RESEARCH \\ 1050 Massachusetts Avenue \\ Cambridge, MA 02138 \\ September 2005
}

Gianmarco I.P. Ottaviano, Department of Economics, University of Bologna, Strada Maggiore 45, 40125 Bologna, Italy. Email: ottavian@economia.unibo.it. Giovanni Peri, Department of Economics, UC Davis, One Shields Avenue, Davis, CA 95616. Email: gperi@ucdavis.edu. We thank Moshe Buchinski, Jan Bruekner, Gerri Carlino, Gordon Hanson, Francesc Ortega, Ronald Rogowski, Duncan Thomas, Etienne Wasmer and participants to seminars at the NBER ITI group, CEPR ERWIT, University of Southern California, UC Irvine, UCLA, UC Riverside, Claremont McKenna College and the Philadelphia FED for helpful comments and discussion. Ahmed Rahman provided invaluable help in the editing of the paper. Ottaviano is grateful to FEEM and MIUR for financial support. Peri acknowledges the UCLA International Institute for partially funding this project. Errors are ours. The views expressed herein are those of the author(s) and do not necessarily reflect the views of the National Bureau of Economic Research.

(C2005 by Gianmarco I.P. Ottaviano and Giovanni Peri. All rights reserved. Short sections of text, not to exceed two paragraphs, may be quoted without explicit permission provided that full credit, including (C) notice, is given to the source. 
Rethinking the Gains from Immigration: Theory and Evidence from the U.S.

Gianmarco I.P. Ottaviano and Giovanni Peri

NBER Working Paper No. 11672

September 2005

JEL No. F22, J61, J31, R13

\section{$\underline{\text { ABSTRACT }}$}

Recent influential empirical work has emphasized the negative impact immigrants have on the wages of U.S.-born workers, arguing that immigration harms less educated American workers in particular and all U.S.-born workers in general. Because U.S. and foreign born workers belong to different skill groups that are imperfectly substitutable, one needs to articulate a production function that aggregates different types of labor (and accounts for complementarity and substitution effects) in order to calculate the various effects of immigrant labor on U.S.-born labor. We introduce such a production function, making the crucial assumption that U.S. and foreign-born workers with similar education and experience levels may nevertheless be imperfectly substitutable, and allowing for endogenous capital accumulation. This function successfully accounts for the negative impact of the relative skill levels of immigrants on the relative wages of U.S. workers. However, contrary to the findings of previous literature, overall immigration generates a large positive effect on the average wages of U.S.-born workers. We show evidence of this positive effect by estimating the impact of immigration on both average wages and housing values across U.S. metropolitan areas (1970-2000). We also reproduce this positive effect by simulating the behavior of average wages and housing prices in an open city-economy, with optimizing U.S.-born agents who respond to an inflow of foreign-born workers of the size and composition comparable to the immigration of the 1990s.

Gianmarco I.P. Ottaviano

Dip. di Scienze Economiche

Università di Bologna

Strada Maggiore 45

40125 Bologna

ITALY

ottavian@economia.unibo.it
Giovanni Peri

Department of Economics

University of California, Davis

One Shields Avenue

Davis, CA 95616

and NBER

gperi@ucdavis.edu 


\section{Introduction}

The United States has experienced a surge of immigration for the last three decades. As Figure 1 illustrates, the percentage of foreign-born residents in the United States has been steadily growing since 1970, and reached a proportion of $13 \%$ of the population by $2003^{1}$. Economists, demographers and social scientists have used both theoretical models and empirical analysis to gauge the impact of these immigrants on the U.S. economy, and on its native residents in particular. The National Research Council (1997) produced a 430 page volume analyzing the characteristics and effects of immigration on American society; since then, a number of other studies have re-examined and re-analyzed the issue. While the debate on several specific findings is still open, the recent analysis of the impact of the foreign-born on U.S.-born seems to have focused its attention on certain issues and set aside others. Our paper wishes to take a fresh look at the overall issue, emphasize important connections between economic theory and empirical findings, and provide a coherent framework to measure the impact of immigration on the average productivity of U.S. natives.

The question we tackle is: what is the impact of immigration on the productivity and income of workers born in the United States? The question really has two parts. The first is imbued with a macro flavor: does the inflow of foreign born workers have a positive or negative net effect on the average production and income of U.S. born residents? This question supposes that we aggregate the wages and incomes of quite heterogeneous U.S. workers. The second question is more micro in focus: how are the gains and losses from immigration distributed across U.S. born workers with different skills, and between labor and physical capital? The consensus emerging from the recent literature is that the effects of immigration on the average (aggregate) income accruing to U.S. natives is rather small. Quantifications of this effect (such as in Borjas, 1995) imply that the sum total of foreign born workers accounts for a mere $0.1 \%$ increase in the average income (from labor and capital) of U.S. born residents. Therefore, the argument goes, one can neglect this minuscule average effect and concentrate solely on the second question dealing with the distributional effects of immigration. Moreover, as immigrants are normally endowed with little physical capital (since few can transport their private homes or enterprises into the U.S.) most of the literature (e.g. Borjas 1995, 2003) represents immigration as an increase in the labor supply with a constant capital stock, and so readily finds a negative impact of immigration on average wages and a positive impact of immigration on the return to capital (due to complementarities between the two factors). The "macro" aspects of the issue (related to average income and average wage income) have been analyzed much more superficially, however, then the "micro" aspects. Most of the recent debate has focused on the effects of immigration on the relative wages of more and less educated U.S. born workers. Some economists argue in favor of a large relative impact (Borjas, 1994, 1999, 2003; Borjas, Freeman and Katz, 1997) while others

\footnotetext{
${ }^{1}$ While remarkable, such rapid increases are not unprecedented for the U.S. Large inflows from Europe during the period 1880-1910 brought the percentage of foreign-born very close to $15 \%$ around the year 1910, and previous episodes of very intense immigration (e.g. 1.5 million Irish immigrants between 1845 and 1854, in the wake of a great famine) caused similar surges.
} 
favor a smaller, barely significant effect (Butcher and Card, 1991; Card, 2001; Lewis, 2003). While the size and significance of these relative wage effects from immigration remain controversial, this paper intends to combine this analysis with the analysis of average wage effects, which have rashly and facilely been considered settled (or unapproachable, or irrelevant) in the literature. As such we nest the "macro" (average) and the "micro" (distributional) aspects of the problem within the same framework.

The effects of immigration on the average wage of U.S. born individuals are extremely difficult (if not impossible) to estimate directly with aggregate U.S. data. Time series of aggregate U.S. wage and immigration numbers after World War II contain only few dozens of observations, and the perennial issues of omitted variable bias and endogeneity make the inference of causality from measured correlations a daunting task. The reported effects of migration on average wages found in the literature have been calculated (rather than estimated) using very simple aggregate production functions and imposing crucial restrictions on the substitutability of skills and the supply of factors (labor and capital). We will argue that these assumptions made in the literature, which produce estimates implying that immigration has negligible effects on the total income of U.S. born residents and negative effects on the average wages of U.S. born workers, may not be the most appropriate. Treating the issues of skill complementarities and physical capital accumulation more carefully, we uncover positive effects of immigration on the average wages and incomes of natives. We analyze this crucial point by employing estimation and simulation exercises on both aggregate data and data from metropolitan areas.

The modern analysis of the effects of immigrant inflows on the wages of natives began with studies (such as Grossman 1982; Altonji and Card 1991) that treated the foreign-born simply as a single homogeneous group of workers, imperfectly substitutable with U.S.-born workers (though possibly divisible into sub-groups). A number of studies on the relative supply of skills and relative wages of U.S. born workers (such as Katz and Murphy 1992; Card and Lemieux 2001) make clear, however, that workers with different levels of schooling and experience are better considered as imperfectly substitutable factors. As a consequence, more recent analysis of the impact of immigration on the wages of U.S. born workers has been carried out partitioning workers among imperfectly substitutable groups (by education and experience) while assuming perfect substitution of native and foreign-born workers within each group (e.g. Card 2001 and Borjas 2003).

Our paper combines the first and second approaches, in the sense that both cases can be seen as special examples nested in our more general framework. We assume the existence of an aggregate production function that combines workers and physical capital, while using education, experience and place of origin (U.S. versus elsewhere) to categorize imperfectly substitutable groups. Following Borjas (2003) we choose a constant elasticity of substitution (CES) form for production, and we nest two groups (U.S. born and foreign born workers) within eight experience groups, and these in turn into four educational attainment groups. This allows for the imperfect substitutability of individuals both of different country origins and of different education-experience levels. 
This imperfect substitutability may arise from different training, occupational choices and various unobserved characteristics of workers from the U.S. and elsewhere. While intuition suggests that a Chinese-born cook is not a perfect substitute for an American cook, and that an Italian tailor and a French architect differ from their U.S. counterparts, the degree of substitutability between the foreign and U.S. born must ultimately be determined empirically. Finally, we include physical capital in production, and treat its accumulation as endogenously driven by market forces that equalize real returns to capital in the long run. ${ }^{2}$ This is also a departure from the literature, which mostly assumes a fixed capital stock when evaluating the distributional effects of immigration. In summary then, our production function can be used to calculate the relative, absolute and average wage effects from the recent inflow of immigrants, as well as simulate the effects of counter-factual scenarios.

In the first part of the paper we estimate the elasticity of substitution between foreign and U.S.-born workers within education-experience cells using data from U.S. censuses from 1970 to 2000. Adopting an empirical methodology similar to Borjas (2003) we find that the data support imperfect substitutability between the two groups. In particular, among the college educated the elasticity of substitution between U.S. and foreign born is around four, while among high-school dropouts it is around seven. This elasticity grows larger (around 10) for intermediately educated groups. Using both these estimates, and previous estimates of the elasticity of substitution between experience groups (Card and Lemieux 2001) and educational groups (Katz and Murphy 1992) we can calculate the effects of immigration during the 1990s on relative wages, or on absolute wages by education group, or on the average wages of U.S.-born workers. For our preferred parameter choice, we calculate that the average wage of U.S. born workers experienced an increase between $2 \%$ and $2.5 \%$ in response to the inflow of foreign-born workers in the 1990-2000 period (equal to $8 \%$ of the U.S. labor force in 1990). At the same time, the inflow lowered the real wage of native workers without a high school degree by $1 \%$, but increased the real wage of native workers with at least a high-school degree as much as $3-4 \%$. We then compare these elasticities (calculated using the CES production and structural parameters) with direct empirical estimates (either produced originally or taken from the literature) that use reduced-form regressions of U.S. wages on immigration flows. We use national data to estimate the effects of relative immigration by skill-group on relative U.S. wages (reproducing the results of Borjas 2003) and metropolitan-area data to estimate the absolute effect of immigration on the wages of each educational group. These direct estimates match rather closely the elasticities calculated using the CES production function for each education group.

Because these large positive effects from immigration on average U.S. wages we obtain from CES-based calculations are novel to the literature, and as such are likely to be controversial, we analyze them further. As mentioned above the average effect of immigration on the marginal productivity of U.S.-born workers is impossible to isolate from aggregate data. So continuing our empirical and theoretical analysis, we concentrate

\footnotetext{
${ }^{2}$ Constant real returns to capital (in the long run) is an implication from classical growth models such as Solow (1956) or Ramsey (1928) as well as open economy macro models.
} 
on the panel variations across U.S. metropolitan areas over time, and exploit the differences in migration inflows and growth rates of the average wage of U.S. born residents. We first present evidence (referring to previous work of ours such as Ottaviano and Peri 2005, and Ottaviano and Peri, forthcoming) that both the average wage and the value of housing for U.S. born residents were positively associated with inflows of foreign-born workers across metropolitan areas. This positive and significant effect survives 2SLS estimation, using instruments which should be exogenous to city-specific unobservable productivity shocks that might bias OLS estimates. We build this instrument by using the initial share of foreign-born workers in a city, grouped by country of origin, and attributing to each group the average immigration rate for that nationality during each decade in the period (1970-2000). First introduced by Card (2001), this instrument will be correlated with actual immigration in the metropolitan area if new immigrants tend to settle prevalently where fellow countrymen already live. On the other hand this constructed variable is independent of any city-shock and, in particular, totally orthogonal to any economic determinant of immigration into the city during the considered decades.

The empirical strategy of using cross-city variations in the relative wages of native workers to estimate the impact of the relative supplies of immigrants has been widely used in the literature (Card 1991, Butcher and Card 1991, Card and Di Nardo 2000). However it has also been widely criticized (Borjas, Freeman and Katz 1997) on the grounds that U.S. born workers can simply move across cities, thus arbitraging away any wage differences generated by differential immigration flows. While labor is not perfectly mobile, surely large real wages differentials will be arbitraged away in the long run, particularly given the high degree of mobility of U.S. workers. To justify our empirical findings using metropolitan data, and to further corroborate the positive effects of immigration on the average wage of U.S.-born workers, we embed our original CES production function into a model that also includes consumption and housing decisions in an open city, and assumes the perfect mobility of U.S.-born workers and firms into and out of the city. Due to the mechanisms of complementarity and endogenous capital accumulation (operating through the CES function), an inflow of foreign-born workers in a city increases the average wage of the U.S.-born. In an open city this would tend to attract more U.S.-born residents, but the larger numbers of people and wages would generate upward pressure on the price of housing (whose supply is constrained by land). A new equilibrium is reached when the local price index (driven by housing prices) offsets the nominal wage gains enjoyed by U.S.-born workers. Average real wages for U.S.-born workers are equated between the immigration city and other cities after the immigration shock. Therefore the equilibrium adjustment triggered by immigration at the city-level implies a positive average effect on the wages of U.S.-born workers that is not entirely eliminated by mobility, for a large part of this adjustment takes place in the form of higher prices for housing (which equalize real wages across cities) rather than migration (which equalize nominal wages across cities). The model thus allows us to simulate the effects that an inflow of foreign-born have on the average wages of and the average value of housing for American-born residents. Using 
immigrant inflows which simulate the experience of the average U.S. metropolitan area in the 1990s (in terms of magnitude and skill composition), we generate effects on wages and housing values very similar to those estimated above using data from these metropolitan areas.

The remainder of the paper is organized as follows. In section 2 we introduce the aggregate CES production function in order to estimate the elasticities of substitution between U.S. and foreign-born workers within each education group. Then, using structural parameters (from both our estimates and the literature) and this production function, we calculate the impact of immigration in the 1990s on the relative, absolute and average wages of U.S.-born workers. Section 3 presents direct estimates (again, both ours and those of previous studies) of the impact of the relative skills of immigrants on relative U.S. wages using national data, and compares them with the values obtained from the CES production function. We then concentrate on the effect immigrants have on average U.S. wages. Empirically we move to a cross-city panel analysis, exploiting the variation of immigrant inflows and wage changes across US cities from 1970 to 2000. Both OLS and 2SLS estimates find positive and significant effects of immigration on the average wages and value of houses for the U.S.-born. These effects are entirely consistent with the positive aggregate effects of immigration on the wages of U.S.-born workers calculated in 2. Section 4 provides a model of production-consumption-housing in an open-city economy; we use this to simulate the impact of immigration during the 1990s on the wages and housing values for U.S. workers. Using plausible structural parameters, the model matches very closely the quantitative effects estimated in the previous section. Section 5 concludes the paper.

\section{Production, Complementarities and Gains from Migration}

Both U.S. natives and foreign born workers can be differentiated into several imperfectly substitutable skill groups (classified by education and experience). Naturally one could directly estimate the partial elasticities of substitution between groups even without an explicit production function. But without assuming a functional form for production, it would be impossible to calculate the effects of a change in the supply of immigrants belonging to several different skill groups on the marginal productivity (wages) of natives from different skill groups. Thus following Borjas (2003), we choose a nested constant elasticity of substitution (CES) production function, in which physical capital and different types of labor are combined to produce output. Labor types are grouped according to education and experience characteristics. We impose lower substitutability between groups of different schooling levels than between groups of different experience levels but with the same schooling. U.S.born and foreign-born laborers are allowed a further degree of imperfect substitutability even when they have the same education and experience. Notationally the production function we use is the following:

$$
Y=A \widetilde{C}^{\alpha} K^{1-\alpha}
$$


where $Y$ is aggregate output, $A$ is total factor productivity, $K$ is physical capital and $\widetilde{C}$ is a CES aggregate of several, imperfectly substitutable types of workers. The production function described above exhibits constant returns to scale $(\mathrm{CRS})$ in capital $K$ and labor $\widetilde{C}$. It describes production in the aggregate U.S. economy. In this section we will use this function to analyze the behavior of the national wages of U.S.-born residents in response to migration. However we can think of the nation as an aggregate of several cities with similar (CRS) production functions. In section 4 we use the same function (1) to represent the production of the average U.S. city. The elasticity of output to the labor aggregate is $\alpha$, while $\widetilde{C}$ is defined as:

$$
\widetilde{C}=\left[\sum_{k=1}^{4}\left(\frac{C_{k}}{\tau_{k}}\right)^{\frac{\delta-1}{\delta}}\right]^{\frac{\delta}{\delta-1}}
$$

$C_{k}$ is an aggregate measure of labor with educational level $k ; \frac{1}{\tau_{k}}$ are group-specific productivity levels. As is standard in the labor literature (see Borjas 2003; Card and Lemieux 2001) we group educational achievements into four categories: High School Dropouts (denoted as $H S D$ ), High School Graduates $(H S G)$, College Dropouts $(C O D)$ and College Graduates $(C O G)$, so that $k=H S D, H S G, C O D, C O G$. The parameter $\delta$ measures the elasticity of substitution between workers with different educational achievements. Within each educational group we assume that workers with different experience levels are also imperfect substitutes. In particular, following the specification used in Card and Lemieux (2001) we write:

$$
\frac{C_{k}}{\tau_{k}}=\left[\sum_{j=1}^{8}\left(\frac{C_{k j}}{\tau_{k j}}\right)^{\frac{\theta-1}{\theta}}\right]^{\frac{\theta}{\theta-1}}
$$

where $j$ is an index spanning experience intervals of five years between 0 and 40 years, so that $j=1$ captures workers with $0-5$ years of experience, $j=2$ those with $6-10$ years, and so on. The parameter $\theta$ measures the elasticity of substitution between workers in the same education group but with different experience levels. As we expect workers within an education group to be closer substitutes than workers across them, our parameter choice (consistent with the findings of the general literature) implies $\theta>\delta$. Finally, distinct from the recent literature, we define $\frac{C_{k j}}{\tau_{k j}}$ as a CES aggregate of home-born and foreign-born workers with schooling $k$ and experience $j$, (denoted, respectively, as $H_{k j}$ and $F_{k j}$ ) in the following way:

$$
\frac{C_{k j}}{\tau_{k j}}=\left[\left(\frac{H_{k j}}{\tau_{H k j}}\right)^{\frac{\sigma k-1}{\sigma k}}+\left(\frac{F_{k j}}{\tau_{F k j}}\right)^{\frac{\sigma k-1}{\sigma k}}\right]^{\frac{\sigma k}{\sigma k-1}}
$$

Since foreign-born workers receive part of their education abroad, they are likely to retain different abilities pertaining to language, quantitative-skills, and so on. Therefore they should be differentiated enough to be 
treated as imperfect substitutes for U.S.-born workers, even within the same education and experience group. Ultimately we allow the empirical analysis to reveal whether their elasticity of substitution with U.S.-born workers in the same education-experience group, $\sigma_{k}$, is finite (imperfect substitutes) or infinite (perfect substitutes). As indicated by the subscript $k$ we allow the elasticity of substitution between the U.S. and foreign born to differ across schooling groups (more on this below). The terms $1 / \tau_{F k j}$ and $1 / \tau_{H k j}$ measure the respective productivity levels of foreign workers and home-born workers.

Since we use decennial data to evaluate the impact of immigration on U.S. wages, it seems reasonable to treat physical capital as endogenously accumulated, rather than fixed. If we assume international capital mobility or, alternatively, accumulation of capital following the Ramsey (1928) or Solow (1956) models, then in the long run (that is, on the balanced growth path) both the real interest rate $r$ and the aggregate capital-output ratio $K / Y$ will be constant. Given that the American economy has not exhibited any permanent trend in real interest rates and has exhibited a roughly constant capital-output ratio for the last century, we make the assumption that the U.S. is on its BGP on solid empirical ground. Since physical capital adjusts in order to maintain a constant interest rate (i.e. towards the BGP) we can solve $K$ out of the production function, and hence write output as a linear function of the labor composite:

$$
Y=\left(\frac{1-\alpha}{r}\right)^{\frac{1-\alpha}{\alpha}} A \widetilde{C}=\widehat{A} \widetilde{C}
$$

where $\widehat{A}=\left(\frac{1-\alpha}{r}\right)^{\frac{1-\alpha}{\alpha}} A$ absorbs a constant into the TFP factor. Expression (5) shows that income per worker grows at the rate of exogenous technology, $A$ (as in any neoclassical growth model) and therefore, in the longrun, the elasticity of income to the labor composite $\widetilde{C}$ is one. When calculating the long-run elasticities of wages to the supply of different kinds of workers, we will use the production function in (5). ${ }^{3}$

\section{$2.1 \quad$ Partial Wage Elasticities}

Using the production function (5) and the definitions (2), (3) and (4) we can obtain the (natural logarithm of) the marginal productivity of U.S.-born workers in group $k j$, which in a competitive market will equal their (logged) wage, $w_{H k j}$ :

$$
\ln \left(w_{H k j}\right)=\ln \widetilde{A}+\frac{1}{\delta} \ln (\widetilde{C})+\ln \Phi_{k}-\left(\frac{1}{\delta}-\frac{1}{\theta}\right) \ln \left(C_{k}\right)+\ln \Phi_{k j}-\left(\frac{1}{\theta}-\frac{1}{\sigma k}\right) \ln \left(C_{k j}\right)+\ln \Phi_{k j H}-\frac{1}{\sigma k} \ln \left(H_{k}\right)
$$

The term $\Phi_{k}$ contains all terms in $\tau_{k}, \Phi_{k j}$ contains the term $\tau_{k j}$ and $\Phi_{k j H}$ contains $\tau_{k j H}$. Expression (6) can

\footnotetext{
${ }^{3}$ This highlights one important difference with Borjas (2003) who, in calculating the long-run elasticities of wages to inflows of immigrants over twenty years, assumes a constant stock of capital.
} 
be used to derive several wage elasticities, i.e., percentage variations of the wages of U.S. workers in response to percentage variations in the supply of foreign-born workers, keeping the efficiency terms fixed. The first elasticity considered is the percentage change in the wage of U.S.-born workers of skill group $k j$ in response to a percentage change of foreign-born workers in the same skill group $k j$, keeping supply of other factors fixed. We call this elasticity $\gamma_{w k j}^{o w n}$, with the subscript indicating that we are focusing on the wage $(w)$ of skill group $k j$ of home-born workers, and the superscript emphasizing the fact that we are changing the supply only of foreign-born workers of the same skill group. It is straightforward to show that this elasticity can be calculated as:

$$
\gamma_{w k j}^{o w n}=\frac{\Delta w_{H k j} / w_{H k j}}{\Delta F_{k j} / L_{k j}}=\left[\frac{1}{\delta}+\left(\frac{1}{\theta}-\frac{1}{\delta}\right)\left(\frac{1}{s_{k}}\right)+\left(\frac{1}{\sigma_{k}}-\frac{1}{\theta}\right)\left(\frac{1}{s_{k j}}\right)\right] \frac{s_{F k j}}{\varkappa_{F k j}} \varkappa_{k j}
$$

where we express, as customarily done in the empirical analysis, the (decennial) change in foreign-born $\Delta F_{k}$ as a percentage of the total initial supply of labor in skill group $k j, L_{k j}$, namely $\frac{\Delta F_{k j}}{L_{k j}}=\left(F_{k j t+10}-F_{k j t}\right) /\left(F_{k j t}+\right.$ $\left.H_{k j t}\right)$. The variable $s_{F k j}$ is equal to the share of overall wages paid to foreign workers in skill group $k j$, $\frac{w_{F k j} F_{k j}}{\sum_{m} \sum_{i}\left(w_{F m i} F_{m i}+w_{H m i} H_{m i}\right)}$, while the variable $\varkappa_{F k j}$ equals $\frac{F_{k j}}{\sum_{m} \sum_{i}\left(F_{m i}+H_{m i}\right)}$, the share of total employment represented by foreign-born workers in skill group $k j$. Analogously $\varkappa_{k j}=\frac{\left(F_{k j}+H_{k j}\right)}{\sum_{m} \sum_{i}\left(F_{m i}+H_{m i}\right)}$ denotes the share of total employment accounted for by workers (both foreign and U.S. born) in skill group $k j$. An interesting variation of the above partial elasticity can be calculated and compared with several existing estimates from the applied literature (see below). The elasticity of wage $w_{H k j}$ to a change in the supply of $F_{k j}$, keeping total production and the intermediate labor composite $C_{k}$ fixed, is given by:

$$
\overline{\gamma_{w k j}^{o w n}}=\left|\frac{\Delta w_{H k j} / w_{H k j}}{\Delta F_{k j} / L_{k j}}\right|_{C_{k}, \widetilde{C} \text { constant }}=\left(\frac{1}{\sigma_{k}}-\frac{1}{\theta}\right)\left(\frac{s_{F k j}}{s_{k j}}\right)\left(\frac{\varkappa_{k j}}{\varkappa_{F k j}}\right)
$$

The elasticity in (8) is obtained from equation (6) by keeping the terms $\ln (\widetilde{C})$ and $\ln \left(C_{k}\right)$ constant and computing only the partial variation of $(\log )$ wage $w_{H k j}$ in response to a variation in $F_{k j}$ that operates through the term $\left(\frac{1}{\theta}-\frac{1}{\sigma k}\right) \ln \left(C_{k j}\right)$. Its empirical equivalent is the elasticity obtained (for instance in Borjas 2003), by regressing the $(\log )$ wages of home-born workers on the change in supply of foreign-born workers in the same education-experience group, absorbing through time and education by time fixed effects the variations operating through terms $\ln (\widetilde{C})$ and $\ln \left(C_{k}\right)$. The elasticity $\overline{\gamma_{w k j}^{o w n}}$ has been considered particularly interesting, for if U.S.-born and foreigners within each skill group $k j$ were perfect substitutes in proportions of one-to-one, then $1 / \tau_{F k j}=1 / \tau_{H k j}=1$ and $\frac{1}{\sigma_{k}}=0$, implying that $\left(\frac{s_{F k j}}{s_{k j}}\right)\left(\frac{\varkappa_{k j}}{\varkappa_{F k j}}\right)=1$ and that the elasticity is equal to $-\frac{1}{\theta}$, which is simply the inverse of the elasticity of substitution between two groups with different experience levels within an education group. While in this case $\overline{\gamma_{w k j}^{o w n}}$ would be equal to a "structural" parameter of the production function, under our more general assumption it is not. Moreover, imperfect substitutability between 
U.S. born and foreign born workers implies that $\overline{\gamma_{w k j}^{o w n}}$, while generally still negative, is smaller in absolute value than $\frac{1}{\theta}$.

A third interesting partial elasticity, also comparable with existing empirical estimates in Borjas (2003) (and partially with Card 2001), is the wage elasticity for U.S. born workers of skill-group $k j$ to the total inflow of foreigners within education group $k$ (of any experience level), keeping total production constant. We define

this elasticity as $\overline{\gamma_{w k j}^{\text {own edu }}}$, where the superscript indicates that we are only changing the supply of foreign born workers in the same education group $k$, the subscript refers to the wage $(w)$ of skill group $k j$, and the upper bar reminds us that total production remains constant. Its expression is:

$$
\overline{\gamma_{w k j}^{\text {own edu }}}=\left|\frac{\Delta w_{H k j} / w_{H k j}}{\Delta F_{k} / L_{k}}\right|_{\widetilde{C} \text { constant }}=\left(\frac{1}{\sigma_{k}}-\frac{1}{\theta}\right)\left(\frac{1}{s_{k j}}\right)\left(\frac{s_{F k j}}{\varkappa_{F k j}}\right) \frac{\Delta F_{k j}}{L_{k}}+\left(\frac{1}{\theta}-\frac{1}{\delta}\right)\left(\frac{1}{s_{k}}\right) \sum_{i} \frac{s_{F k i}}{\varkappa_{F k i}} \frac{\Delta F_{k i}}{L_{k}}
$$

The first portion of the summation on the right hand side captures the effect on $w_{H k j}$ from a change in the supply of foreign-born in the same education-experience group, keeping $C_{k}$ constant. The second portion captures the effect of changes in the supply of foreign-born in each experience group within education group $k$. These effects operate through changes in the term $\ln \left(C_{k}\right)$ (see equation 6).

\subsection{The Impact of Immigration on Wages}

While the partial elasticities $\gamma_{w k j}^{o w n}, \overline{\gamma_{w k j}^{o w n}}$ and $\overline{\gamma_{w k j}^{o w n e d u}}$ each provide important information concerning the movement of wages of U.S.-born workers within each skill group in reaction to immigrant inflows from that group, they do not tell us much about the total effect of immigration on the wages of native workers. Total immigration will affect wages (of U.S. born workers) through both "own" and "cross" elasticities. In fact presumably, due to complementarities, cross effects are likely to be positive even while own elasticity effects on wages are negative. Using equation (6) we can define and calculate $\gamma_{w k j}^{t o t a l}$; this is the net percentage change in the wages of U.S.-born workers within skill group $k j$ in response to an increase in the supply of foreigners from all skill groups, $j=1,2 \ldots 8$ and $k=1,2 . .4$. The elasticity is equal to:

$$
\gamma_{w k j}^{t o t a l}=\frac{\Delta w_{H k j} / w_{H k j}}{\Delta F / L}=\frac{\left(\frac{1}{\sigma_{k}}-\frac{1}{\theta}\right)\left(\frac{1}{s_{k j}}\right)\left(\frac{s_{F k j}}{\varkappa_{F k j}}\right) \frac{\Delta F_{k j}}{L}+\left(\frac{1}{\theta}-\frac{1}{\delta}\right)\left(\frac{1}{s_{k}}\right) \sum_{i} \frac{s_{F k i}}{\varkappa_{F k i}} \frac{\Delta F_{k i}}{L}+\frac{1}{\delta} \sum_{m} \sum_{i} \frac{s_{F m i}}{\varkappa_{F k m}} \frac{\Delta F_{m i}}{L}}{\Delta F / L}
$$

where $\Delta F / L=\sum_{m} \sum_{i} \frac{\Delta F_{m i}}{L}, L$ is the total initial employment, and the other variables are defined as above.

The numerator of (10) contains three terms added together. The last term (double summation) captures the 
positive effect from immigration in all education and experience groups due to complementarities with U.S.born workers, the intermediate term captures the additional (negative) impact of immigration within the same education group only (due to closer substitutability with the home born in group $k j$ ), and the first term captures the additional (negative) impact of immigration within the same education-experience group (due to even closer substitutability with home workers in group $k j$ ). Each term depends on combinations of the elasticities and on the number of immigrants from each group $\left(\frac{\Delta F_{k i}}{L}\right)$. Finally, aggregating the changes in wages of all U.S.-born workers from migration, and weighting them according to the wage share of their respective skill-group, we obtain the elasticity of the average wage of U.S.-born workers to the total change in supply due to immigration. This elasticity, denoted as $\gamma_{w}$, measures in percentage terms the overall gain (if positive) or loss (if negative) accruing to U.S. labor income as a consequence of immigration. This elasticity is obtained as follows:

$$
\gamma_{w}=\frac{\Delta \bar{w}_{H} / \bar{w}_{H}}{\Delta F / L}=\sum_{k} \sum_{j} s_{k j} \frac{\Delta w_{H k j} / w_{H k j}}{\Delta F / L}
$$

\subsection{Estimates of Substitutability between U.S.-born and Foreign-born}

In order to calculate the partial elasticities $\gamma_{w k j}^{o w n}, \overline{\gamma_{w k j}^{o w n}}$ and $\gamma_{w k j}^{o w n}$ edu together with the total effects $\gamma_{w k j}^{\text {total }}$ and $\gamma_{w}$, we require only three sets of parameters: $\delta, \theta, \sigma_{k}{ }^{4}$ The parameter $\delta$ is the elasticity of substitution between groups of workers with different educational attainment levels. Several existing empirical studies have estimated this parameter using either only micro data on U.S. native workers or aggregate data. ${ }^{5}$ Most of the existing estimates cluster between 1.5 and 2. The substitutability between workers of different experience levels, $\theta$, has also been estimated in recent articles; perhaps most notably, Card and Lemieux (2001) produce estimates in the range between 3 and 4 . We will use these values in our calculations. The parameters $\sigma_{k}$, $(k=H S D, H S G, C O D, C O G)$, which capture the imperfect substitutability between the U.S. and foreign born in the same skill group, have never before been estimated. Our production function, however, provides a convenient framework to estimate these parameters. Taking the ratio of the logged wages of U.S. and foreignborn workers within the same skill group, we obtain the following relation:

$$
\ln \left(w_{H k j t} / w_{F k j t}\right)=-\frac{1}{\sigma_{k}} \ln \left(H_{k j t} / F_{k j t}\right)-\frac{\sigma_{k}-1}{\sigma_{k}} \ln \left(\tau_{H k j t} / \tau_{F k j t}\right)
$$

Equation (12) provides the basis necessary to estimate the parameters $\sigma_{k}$. We wish to identify some variation in the relative employment of U.S. and foreign born workers of skill-group $k j$ in year $t, H_{k j t} / F_{k j t}$, which is driven by exogenous (supply) shifts and is orthogonal to changes in relative productivity $\tau_{H k j t} / \tau_{F k j t}$. We can then use this variation as an instrument in the 2SLS estimation of the coefficient $-\frac{1}{\sigma_{k}}$ in equation (12). Following Borjas

\footnotetext{
${ }^{4}$ Of course we also need the shares of employment and total wage payments for each skill group.

${ }^{5}$ Katz and Murphy (1992), Angrist (1995), and Ciccone and Peri (2005) are among recent works estimating this elasticity. Hamermesh (1992) Chapter 3 reviews estimates in earlier literature.
} 
(2003), we assume that once we control for education by year $\left(D_{k t}\right)$, experience by year $\left(D_{j t}\right)$, and experience by education fixed effects $\left(D_{k j}\right)$, the inflow of foreign-born workers within a particular skill-group provides an exogenous shift in supply. The idea here is that the distribution of an influx of immigrants across experiences groups but within an education group is exogenous to U.S. productivity shocks. As such we run the regression:

$$
\ln \left(w_{H k j t} / w_{F k j t}\right)=D_{k j}+D_{k t}+D_{j t}-\frac{1}{\sigma_{k}} \ln \left(H_{k j t} / F_{k j t}\right)+\varepsilon_{k j t}
$$

and use the variable $\ln \left(1 / F_{k j t}\right)$ as an instrument for $\ln \left(H_{k j t} / F_{k j t}\right)$. We use country-level data from IPUMS 1970, 1980, 1990 and 2000, and divide groups based on education and experience as described above. ${ }^{6}$ This generates 128 observations of skill by year, relative wages and relative supplies. We pool all four schooling groups together, and assume either equal elasticities across schooling groups, $\sigma_{k}=\sigma$, or different $\sigma_{k}$ 's for each group. The regressions produce estimates for $-1 / \sigma_{k}$ and their standard errors. We use the delta-method (e.g. Ruud 2000, page 367) to calculate both $\sigma_{k}$ and their relative standard errors, reporting these in Table 1. First let us notice that in spite of relatively large standard errors (due to few degrees of freedom since we control for 80 fixed effects) each estimated coefficient $-1 / \sigma_{k}$ is significantly different from 0 (with the exception of $-1 / \sigma_{C O D}$, from the second column of Table 2). This suggests that foreign-born workers within a skill group are indeed not perfect substitutes for U.S.-born workers, contrary to what is assumed in the literature. Second, while the average elasticity of substitution is 7.7, the estimates in column 2 show remarkably different elasticities for different skill groups. In particular, foreign-born college graduates are the hardest to substitute with U.S. born college graduates (here the elasticity of substitution is around 4). Among high-school dropouts foreigners are somewhat more substitutable for natives (elasticity of 7) while among the intermediate education groups (high school graduates and college dropouts) they are highly substitutable (elasticities range between 10 and 16, although they are very imprecisely estimated).

One might ask if these estimates are reasonable? One might further ask why U.S. and foreign-born workers with similar human capital characteristics are not perfectly substitutable (particularly among the highest and lowest educational groups)? When compared to existing estimates of substitutability of U.S.-born workers across experience groups within a particular education group, we find our estimates very reasonable (which according to Card and Lemieux 2001 should range between 3 and 4). Conceivably native and foreign-born workers should not be much easier to substitute in production than two U.S. born workers with 5 years of experience difference. One reason for this imperfect substitutability is that, for given skills, U.S. and foreign born workers often choose different occupations (see Card 2001 for more detail). This is particularly true for workers with high and low levels of education (rather than with intermediate levels). For instance among the lowly-skilled (HSD), foreign

\footnotetext{
${ }^{6}$ Integrated Public Use Microdata Sample, Ruggles et al. (2005). For a detailed description of how we aggregate the individual data and how we control for personal characteristics see the Appendix.
} 
born workers are highly represented in occupations like tailoring (where $54 \%$ were foreign born in 2000) and plaster-stucco masoning (where 44\% were foreign-born in 2000), while U.S.-born workers are highly represented among, say, crane operators (where less than $1 \%$ was foreign-born in 2000) and sewer-pipe cleaners (where less than $1 \%$ foreign-born). Since one would be hard pressed to call these services perfectly substitutable, there is no reason to believe that payments for such services should be equalized. A similar argument applies for the highly-skilled $(C O G)$. For instance foreign-born workers are highly represented in scientific and technological fields ( $45 \%$ of medical scientists and $33 \%$ of computer engineers are foreign-born) while U.S.-born workers are highly represented among lawyers (less than $4 \%$ are foreign-born) or museum curators and archivists (less than $3 \%$ are foreign-born). Moreover, even within the same profession, often the U.S. and foreign-born provide different services, and hence benefit from complementing each other, regardless of education level. For instance, Chinese and American cooks do not produce similar meals, nor do Italian and American tailors provide identical types of clothes. Similarly, a European-trained physicist (more inclined towards a theoretical approach) is not perfectly substitutable with a U.S.-trained one (more inclined towards an experimental approach), and a French architect will likely create a starkly different building than an American one. All in all, our empirical method produces precise estimates for the imperfect substitutability between U.S. and foreign born workers in both high and low education groups, and these estimates are bourn out by anecdotal evidence. We therefore take the above estimates seriously and use them in our calculations.

One final remark. If immigration has an endogenous component that responds to the relative productivity of skills, a positive correlation would exist between the term $\tau_{H k j t} / \tau_{F k j t}$, which is in the residual of regression (13), and the instrument $\ln \left(F_{k j t}\right)$. This correlation would then bias the estimates of $-\frac{1}{\sigma_{k}}$ towards 0 , and thus bias the value of $\sigma_{k}$ upwards. In our calculations below we therefore consider the estimates of $\sigma_{k}$ as a likely upper bound of the relevant elasticities; consequently we experiment with smaller values.

\subsection{Calculated Effects of Immigration on Wages and Some Counterfactual Exper- iments}

Table 2 shows the calculated effects of an increase in foreign-born workers on the wages of U.S.-born workers. The elasticities are obtained using formulas (8), (9), (10) and (11), and data on wages and employment shares relative to 1990, together with changes in the supply of skills from immigration during 1990-2000, are from the IPUMS of Ruggles et al. (2005). Column (a) reports the calculated partial elasticity of the wages of U.S.-born workers to an immigrant inflow of the same education-experience group, $\overline{\gamma_{w k j}^{o w n}}$, while column (b) reports the partial elasticity of U.S.-born wages to immigrants only in the same education group, $\overline{\gamma_{w k j}^{\text {own edu }}}$. The total effect of immigration on the wages of U.S.-born workers of each skill group, $\gamma_{w k j}^{\text {total }}$ is shown in column (c), while the elasticity of the average wage of U.S.-born workers to total immigration, $\gamma_{w}$, is reported in column (d). 
The final column (e) reports the calculated percentage change in the average wages of U.S.-born workers as a consequence of the 1990-2000 inflow of immigrants. While we calculate $\overline{\gamma_{w k j}^{o w n}}, \gamma_{w k j}^{\text {own edu }}$ and $\gamma_{w k j}^{\text {total for each }}$ education-experience combination, the table only reports the average by education groups (across experience groups). The first three rows of Table 2 show the calculated impact (for different parameter values) of the actual immigration increase in the 1990s. This increase, expressed as the change of foreign-born in each skill-group relative to total initial employment (1990) was: $\Delta f_{H S D}=1.9 \%, \Delta f_{H S G}=1.5 \%, \Delta f_{C O D}=1.6 \% \Delta f_{C O G}=$ $3.0 \%$. While we choose 1.5 and 3 as the consensus values for the parameters $\delta$ and $\theta$ respectively, we show the results for different choices for parameters $\sigma_{k}$. By way of contrast, the last three rows of the table present the effects of some counterfactual immigration flows.

Let us describe these results in turn. Specification 1, reported strictly as a benchmark for comparison, assumes that U.S. and foreign born workers of the same skill group are perfect substitutes. Our estimates of course contradict this assumption that nonetheless is used as the standard one in the literature; it therefore serves as a useful reference. Under this assumption the overall effect on average U.S. wages from the 1990-2000 migratory inflow is very small (elasticity of 0.09 ) but positive. This result is in contrast with the results of Borjas (2003) who finds a strong negative effect of total immigration on average U.S. wages (elasticity -0.3). Borjas' effect is entirely due to his assumption of a fixed capital stock (rather than an endogenously accumulated one, as in our model) which seems extreme for a ten-year span. The small effect on average wages is accompanied, however, by a strong redistributive effect. "Own" elasticities are negative and large: they average around -0.3 for an increased relative supply of foreign-workers in the same education-experience group, and -0.62 for an increased relative supply in the same education group overall. Therefore the relative size of immigrant groups across skills heavily affects the relative wage effects. Converting the elasticities $\gamma_{w k j}^{\text {total }}$ into percentage effects of immigration on U.S. wages, the first row of Table 2 implies that the real wages of high-school dropouts decreased by $4.5 \%$, the wages of workers with a high-school degree increased by $2 \%$, and the wages of college graduates did not change. These differences stem from the fact that immigrants are over-represented among the lowly-skilled, under-represented among the intermediately-skilled, and proportionally represented among the highly-skilled. This U-shaped skill distribution for foreign-born workers generates the relative wage changes calculated in the first row.

Specification 2 calculates the effects of immigration when we use the values of $\sigma_{k}$ estimated in Table 2. We use values of seven and four (very close to our point estimates) as the elasticities of substitution within the lowest and highest education groups, respectively, and a value of ten for the two intermediate groups. Both the effects on the average wage of U.S.-born workers and the effects on the distribution change quite dramatically. First of all, the elasticity of average wages to immigration becomes large and positive. The $8 \%$ increase in foreign-born workers increases the average U.S. wage by $2.2 \%$. Moreover the three top education groups $(H S G, C O D$ and 
$C O G$ ) all gain by significant amounts (around a $2.4 \%$ real wage increase for each in response to this immigration) while only the low-skill group looses (around a $2.4 \%$ wage decrease). A critical thing to note is that while the gains for the intermediately-educated are still driven by the relative supplies of the foreign-born (who are scarce in these groups), the gains for the college educated stem from the lower degree of substitutability between U.S. and foreign-born laborers in this group. Notice however that the own elasticities $\left(\overline{\gamma_{w k j}^{o w n}}\right.$ and $\left.\overline{\gamma_{w k j}^{\text {own edu }}}\right)$ are still significantly negative for each group. Averaging across groups, $\overline{\gamma_{w k j}^{o w n}}$ is around -0.18 and $\overline{\gamma_{w k j}^{\text {own edu }}}$ is around -0.5 (more on this below). Finally, specification 3 assumes an elasticity of substitution somewhat lower than our point estimate from Table 1. This is done in order to account for a potential upward bias that may arise from any endogeneity in the skill composition of immigrants. The chosen values are, however, within two standard deviations from the estimates of Table 1. As we can see, the effect of immigration on average wages here is even more dramatic. Converting elasticities into actual changes, the average wage of U.S. born workers increases by $2.7 \%$, and the most dramatically affected group is that of U.S.-born college graduates, whose wage increases by $3.5 \%$ ! We label this specification as our "preferred" one for reasons that will become clear in the next section, when we compare the calculated elasticities to those empirically estimated from the data in a reduced-form equation.

The last three specifications in Table 2 use our preferred parameter combination to evaluate the effects of some "counterfactual" migratory flows. Focusing briefly only on the overall average effect on the wages of U.S.-born laborers, a few interesting indications emerge. First, if the U.S. were to completely eliminate the immigration of low skilled workers $(H S D)$ and replace them with an equal number of immigrants among the intermediately skilled $(H S G)$, so that total migration remains unchanged, the overall beneficial effects of immigration on the average U.S. wage would decline slightly (it would increase by $2.6 \%$ rather than by $2.7 \%$ ). This results from the relative scarcity of U.S.-born high school dropouts and the higher substitutability between natives and foreigners in the intermediate education groups. Conversely, specification 5 eliminates the inflow of high school graduates in favor of an equal increase in high school dropouts (making even more extreme the over-representation of foreign-born among the group of low educated workers). This move slightly increases the average marginal benefit accrued to U.S. workers via their wages (to 2.75\%). Of course these two policies would generate large effects on relative wages, with the second move exasperating the negative impact on the wages of lowly-skilled U.S. natives (a decrease by over $8 \%$ as result of immigration). The most harmful scenario for average U.S. wages, however, is the one reported in specification 6 , in which the inflow of college graduates is eliminated in favor of an equal increase in college dropouts. In this case the effect of immigration descends from large and positive to essentially 0. Clearly the high complementarities of foreign-born workers in high-skill professions is a key element of the overall gains from migration generated by our model. 


\section{Empirical Estimates}

\subsection{Own Skill-Group Effects: Labor Demands Are Downward Sloping}

The calculations presented in Table 2 show very clearly that it is not only feasible, but it is highly likely, that negative wage elasticities to the supply of foreign workers in the same skill group, $\overline{\gamma_{w k j}^{o w n}}$ and $\overline{\gamma_{w k j}^{\text {own edu }}}$, coexist with positive overall average effects of this supply on U.S. wages $\left(\gamma_{w}\right)$, along with positive total effects on the wages of U.S.-born workers in certain skill groups $\left(\gamma_{w k j}^{\text {total }}\right)$. The elasticities $\overline{\gamma_{w k j}^{o w n}}$ and $\overline{\gamma_{w k j}^{\text {own edu }}}$ are measures of how the relative supply of foreign-skills affects the relative wages of U.S. workers with the same observable skills, keeping total production and total intermediate labor composition constant. They are negative in most reasonably-specified production functions, but cannot be used to evaluate the absolute effects of immigration on the wages of U.S.-born workers unless we embed them into a production function that accounts for substitution and complementarity effects. The above-mentioned empirical literature mostly dismisses the aggregate effects of migration as hardly relevant, and thus has concentrated on the redistributive effects and the estimates of these elasticities. Typically the analysis on the effects of immigration on relative U.S. wages, considering the

U.S. as an integrated labor market segmented by skills, involves estimating a regression such as:

$$
\Delta \ln w_{k j t}=\alpha_{k j}+\beta_{k t}+\beta_{j t}+\left(\overline{\gamma_{w k j}^{o w n}}\right) \Delta f_{k j t}+\varepsilon_{k j t}
$$

In (14) the change in wages for U.S.-born workers in skill group $k j, \Delta \ln w_{k j t}$, depends (once we account for education by time, experience by time, and experience by education effects) on the change in the supply of workers in skill group $k j$ caused by immigration $\left(\Delta f_{k j t}\right)$. This is, for instance, the regression that is run in Borjas (2003) page 1363. We denote the coefficient on $\Delta f_{k j t}$ as $\overline{\gamma_{w k j}^{o w n}}$ because the above regression provides an estimate of the elasticity defined by expression (8). Alternatively, economists have used cross-city variations in the relative supply of foreign-born laborers to identify the effects of this supply on the relative wages of U.S.-born laborers (e.g. Card 2001). Usually in this case the number of skill groups is reduced (to educational groups only) and an accompanying regression is run to check whether changes in the relative employment of U.S.-born workers compensate (and to what extent) for the relative supply shifts due to immigration. ${ }^{7}$ As these regressions typically use the relative changes across educational groups, they provide estimates for the parameter $\overline{\gamma_{w k j}^{\text {own edu }} \text {. }}$

The first column of Table 3 presents a sample of some recent influential estimates for the parameters $\overline{\gamma_{w k j}^{o w n}}$ and $\overline{\gamma_{w k j}^{\text {own edu }}}$, together with our estimates of these coefficients. By way of comparison, the second column of

\footnotetext{
${ }^{7}$ Typically a supplemental regression such as $\Delta n_{c k t}=\alpha_{c k}+\beta_{c t}+\left(\gamma_{E_{k}}\right) \Delta f_{c k t}+\varepsilon_{c k t}^{E}$ is run.

$\Delta n_{\text {ckt }}$ is the change in employment of U.S.-born workers of skill $k$ in city $c$. Once we account for city-by-year fixed effects and city-by-skill fixed effects, $\gamma_{E_{k}}$, captures the impact of an inflow of foreign-born workers on the employment of U.S.-born workers within a particular skill group in a city.
} 
the table shows the calculated values for these elasticities using expressions (8) and (9). The first row of Table 3 shows the estimate of $\overline{\gamma_{w k j}^{o w n}}$ from Borjas (2003), while the second row reports the estimate we obtain when we replicate Borjas' regression using a slightly different sample (1970-2000) and a different definition of wage (hourly rather than weekly). Our estimate is somewhat smaller in absolute value (-0.15 vs. -0.29) and more precise than Borjas', but remains within two standard deviations from his. Both coefficients are estimated using national data in a regression as (14), assuming that the distribution of immigrants across skill groups is exogenous. Our point estimate for the elasticity $\overline{\gamma_{w k j}^{o w n}}$ lands right in the middle of the range calculated in the previous section (between -0.13 and -0.18 choosing specification 2 and 3 of Table 2). Borjas's estimate is outside this range, although because of a large standard error one cannot reject a value from this range.

Specification 3 of Table 3 reports the range of wage elasticities from immigration in workers' "own" skill group, taken from Card 2001. This elasticity is smaller but not far from those illustrated in the previous two rows. Card's estimate cannot, however, be directly compared with the two previous estimates. First, the skill groups chosen by Card are not education-experience-based but occupation-based. Workers are grouped into 6 skill categories, each one defined by the probability of being in a group of occupations; as such our production function would not have a clear prediction on the estimated elasticity. Second, Card (2001) uses only data from the 1990 Census (for 175 metropolitan areas); by experimenting with our data-set we find that these estimates are rather sensitive to the sample specified. While we think that the choice of skill groups and samples may matter, we do not believe that the two common criticisms (proposed by Borjas among others) to city-based elasticity estimates apply here. The first criticism is that internal migration by U.S.- born workers would arbitrage wage differences away. This mechanism, however, would entail a significant association between outflows of U.S.-born workers from a city and inflows of foreign-born workers into the same city. But to the contrary, the most careful studies of the response of native workers to immigration (e.g. Butcher and Card 1991, Card and Di Nardo 2000, Card 2001) show that an inflow of native workers is associated with higher immigration in cities. ${ }^{8}$ Moreover, our model of section 4 shows an alternative mechanism that establishes equilibrium across cities following an inflow of foreign-born workers and allowing for the free mobility of U.S.-born workers. This mechanism does not imply wage equalization as long as there can be changes in city-level prices (i.e. values of housing). The second criticism is that immigration in cities is correlated with city-specific productivity shocks, inducing a correlation between explanatory variables and residuals that biases the estimated elasticity. To address this issue Card (2001) constructs reasonable instruments. Specifically, in order to produce estimates that are less likely to suffer from omitted variable bias, Card considers the initial share (in year 1985) of foreign-born workers in each metropolitan area, using 17 nationality-of-origin groups. For each nationality group he calculates the share of workers within each skill group. He then imputes to each nation-of-origin-by-skill group in each metropolitan

\footnotetext{
${ }^{8}$ There are some early estimates (notably Filer 1992 and Frey 1995) that report the association between native outflows and immigrant inflows in cities. These however are based on restricted samples and less careful empirical strategies.
} 
area the overall immigration rate for that group into the U.S. Aggregating across national groups in each city, this procedure produces a "constructed" increase in the number of foreign-born workers within each skill group in each city. These constructed values are good predictors for the actual values if, as argued by Card (2001), new immigrants settle where people of the same nationality already live. Since the instrument uses only the initial composition of foreign-born residents in a city and subsequent average immigration rates in the U.S. by nationality, it is not correlated with any city-specific factor that would affect actual immigration in the city during the decade. As a consequence it is by construction orthogonal to any city-specific shock to productivity, amenities and labor market conditions.

Row 4 of Table 3 shows the estimates of $\overline{\gamma_{w k j}^{\text {own edu }}}$ from Borjas (2003). Since national data are used (5 census years and only 4 education groups) the reported elasticity is estimated with only 20 observations and is therefore quite imprecise. However, what makes it appealing is that it is not far from existing estimates of the relative wage elasticity to changes in the relative supply of workers in different educational groups (Johnson 1970, Fallon and Layard 1975, Katz and Murply 1992, Angrist 1995, Ciccone and Peri 2005) which range between 0.5 and 0.76. The standard error, however, is so large that even the null hypothesis $\overline{\gamma_{w k j}^{\text {own edu }}}=0$ cannot be rejected. To improve on the precision of these estimates our procedure (in row 5) relies on cross-city regressions, and uses instruments built similarly as those in Card (2001) described above. ${ }^{9}$ We regress the change in wages of U.S.-born workers in the usual four education groups across 86 U.S. cities over 3 decades on changes in employment due to inflows of immigrants. We control for city-by-time and education-by-time fixed effects, and instrument the supply of foreign-born workers using the "constructed" supply. We obtain a point estimate of -0.45 with a standard error of 0.25 , reported in specification 5 of Table 3 . Again our estimate is within two

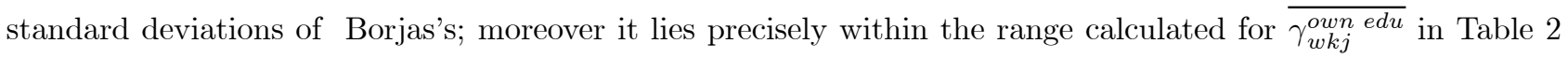
(between -0.50 and -0.45 using specification 2 and 3). Further, both estimates of specifications 4 and 5 mirror or approximate the existing range of estimates for the elasticity of relative wages to the relative supply of workers in different education groups, found in the literature (see Ciccone and Peri 2005 for a survey of those estimates).

\subsection{Total Effects of immigration on wages of different Skill Groups}

Encouraged by the remarkably good match between our calculated "own-skill group" elasticities and those estimated by a "reduced-form" approach in the existing literature, we proceed to compare the calculated effects of Table 2 with direct estimates of the overall effect of immigration on the absolute wages of each skill group, namely the elasticity $\gamma_{w k j}^{\text {total }}$. As we illustrated above, these overall effects depend on negative "own-skill-group" effects as well as on positive (complementarity) effects from changes in the supply of other skills. Empirically, we can run the following four regression:

\footnotetext{
${ }^{9}$ Details on the construction of this instrumental variable are in the Appendix 6 .
} 


$$
\Delta \ln \bar{w}_{c k t}=\alpha_{c}+\beta_{t}+\gamma_{w k}^{t o t a l} \Delta f_{c t}+\varepsilon_{c t}, \text { for } k=H S D, H S G, C O D, C O G
$$

where $\bar{w}_{c k t}$ is the wage of U.S. born workers in education group $k$ for city $c$ and period $t$, while $\Delta f_{c t}$ is the total number of foreign-born workers (relative to initial employment) in city $c$ and period $t$. The existing empirical literature has been hesitant to perform an estimation such as (15) because it is clear that the coefficient $\gamma_{w k}^{\text {total }}$ is not a structural parameter and may vary with the skill-composition of foreign-born workers. In this case however we have a prediction of what $\gamma_{w k}^{\text {total }}$ should be, given the observed distribution of U.S.-born and immigrant workers by skill (1990-2000). Using the constructed share of foreign-born described in appendix 6 as an instrument, and controlling for city and year fixed effects, we can obtain unbiased estimates of $\gamma_{w k}^{\text {total }}$ for each education group. These estimates, reported in Table 4, capture the average (across cities) effect of a 1\% increase in the total supply of foreign-born workers on the wages of U.S. born workers in each group. This elasticity captures directly the effects calculated in column (c) of Table 2. Specification I reports the estimated coefficients using a panel of 86 cities for the censuses between 1970 and 2000. Column II shows the estimates using 113 cities over the censuses $1970-1990 .{ }^{10}$ Column III reports the range of the calculated elasticity from Table 2, column (c), specifications 2 and 3. Each coefficient (cell) in columns I and II of Table 4 is estimated in a separate regression. While the estimates are not very precise, the values of each estimate for each sample are similar. Moreover the estimated coefficients are consistent with those calculated using the CES function. The impact on high school dropouts is estimated to be between -0.10 and -0.20 . The corresponding value calculated using CES production, reported in column III, is -0.30 . The impact on both high school graduates and college dropouts is estimated to be around 0.2 , while the corresponding calculated elasticities are between 0.28 and 0.33 . The estimated effect on college graduates is the only one significantly positive, estimated to be around 0.40 , while the corresponding calculated parameter lies between 0.33 and 0.44 . Again, given the simplification involved in the reduced-form estimation, it is remarkable that the coefficients match up so closely with those calculated using our production function. Two remarks are perhaps in order. First, the positive and significant effect of immigration on U.S.-born college graduates is by itself a sign that within this group complementarities must be strong. In fact, in the context of perfect substitutability and due to relative scarcity alone, we should expect an effect on college graduate wages close to zero (as in the first row of Table 2). Second, by focusing on total effects by skill group, it is already clear that an inflow of foreign born workers has mostly positive effects on the wages of U.S.-born workers. In particular recall that the three groups that benefit from immigration $(H S G, C O D$ and $C O G$ ) account for $92 \%$ of the total U.S.-born labor force in 2000. The losses from migration are concentrated on a very small group which, moreover, has been dramatically shrinking for U.S. natives for the last 30 years.

\footnotetext{
${ }^{10}$ The reduced number of cities for the longer panel is due to the limited availability of the MSA identifier in the IPUMS 2000.
} 


\subsection{Average Effects of Immigration Across Cities: Wages, Value of Housing and Employment}

The previous two sections show that the relative and absolute effects of immigration on the wages of natives obtained using the CES production function match rather well the estimates from reduced-form regressions. The most striking and potentially controversial finding of Table 2 is, however, the large positive overall gains for U.S.-born labor. Since this aggregate effect is impossible to detect from national aggregate data, we aim to measure it by using cross-city variations. Indeed we intend to provide not only empirical evidence in favor of this positive aggregate effect, but also a detailed account of how such an effect can be produced and maintained in a long-run equilibrium. Hence we accompany wage regressions with regressions of cross-city values of housing and changes in employment: as we will show in section 4 a simple general equilibrium model should account for the behavior of wages, rents and employment levels of U.S.-born workers in an open city in response to immigration.

In prior work (Ottaviano and Peri 2005; Ottaviano and Peri, forthcoming) we have detected a positive and very robust relationship between the average wages of U.S.-born workers and the share of foreigners across U.S. cities. These articles separately analyze the wage-rent equilibrium (Ottaviano and Peri 2005) and the wageemployment equilibrium (Ottaviano and Peri, forthcoming), concluding that the simultaneous positive effects of immigration on all the variables analyzed (concerning U.S.-born workers) can only be reconciled with the idea that immigrants tend to provide a positive influence on the productivity of native workers. We have illustrated in section (2) how the overall positive effects on the U.S.-born emerge from the various complementarities of the foreign-born across skills. Here we reproduce some of the wage-employment-rent estimates across cities which confirm these positive effects from immigration on each variable, while in the next section we quantitatively match these estimates with a simple general equilibrium open-city model that incorporates the production function developed above.

Figures 2, 3 and 4 illustrate the correlations between the change in foreign-born workers (as a percentage of total initial employment) and the percentage increase of the average wage of U.S.-born workers (Figure 1), the percentage increase of the average rent per room paid by U.S.-born residents (Figure 2) and the percentage increase in the employment of U.S.-born workers (Figure 3), across the 86 largest metropolitan areas in the United States for the 1970-2000 period. The visual impression here suggests a strong positive correlation between the worker-share of foreign-born and each of the three variables. Metropolitan areas where foreignborn workers abound exhibit faster growth in the average wages, employment, and property values of U.S.-born workers. Without yet suggesting the direction of causality, the described statistics show that more immigrants are associated with all the characteristics of a booming metropolitan economy. For the remainder of this section we analyze more formally these positive correlations in order to understand whether they are likely to be spurious 
or due to omitted variables.

Using the Integrated Public Use Microdata Samples of the U.S. censuses of 1970, 80, 90 and 2000 for individuals in 86 metropolitan areas, we estimate the following three panel regressions: ${ }^{11}$

$$
\Delta n_{c t}=\alpha_{c}+\beta_{t}+\gamma_{E} \Delta f_{c t}+\varepsilon_{c t}^{E}
$$

$$
\Delta \ln \bar{w}_{c t}=\alpha_{c}+\beta_{t}+\gamma_{w} \Delta f_{c t}+\varepsilon_{c t}^{w}
$$

$$
\Delta \ln \bar{r}_{c t}=\alpha_{c}+\beta_{t}+\gamma_{r} \Delta f_{c t}+\varepsilon_{c t}^{r}
$$

Each of these regressions (16)-(18) consider as an explanatory variable $\Delta f_{c t}$, which is the percentage increase of the total employment of city $c$ in decade $t$ due to immigration, defined as the percentage change in employment due to an influx of foreign-born workers (15). Once we control for city fixed effects $\alpha_{c}$ and period fixed effects $\beta_{t}$, and if $\Delta f_{c t}$ is exogenous to the economic conditions of city $c$, then regression (16) estimates the effect of this increase on the increase in employment of U.S.-born workers in city $c$ and decade $t$, as a percentage of the total initial employment, namely $\Delta n_{c t}=\left(H_{c t+10}-H_{c t}\right) /\left(F_{c t}+H_{c t}\right)$. The coefficient $\gamma_{E}$ captures the elasticity of U.S.-born employment to an increase of foreign-born workers. The coefficient $\gamma_{w}$ in regression (17) quantifies the percentage increase in the average real wage (in 2000 constant dollars) of U.S.-born workers in city $c$ and decade $t$ from an increase in foreign-born workers. ${ }^{12}$ Finally coefficient $\gamma_{r}$ in regression (18) quantifies the percentage increase in the real average house value (in 2000 constant dollars) for U.S.-born workers in city $c$ and decade $t$ in response to an increase in foreign-born workers relative to total employment. ${ }^{13}$ Due to city-specific productivity shocks, the variables $\varepsilon_{c t}^{E}, \varepsilon_{c t}^{w}$ and $\varepsilon_{c t}^{r}$ are likely to be correlated with migration flows $\Delta f_{c t}$. We can however use the constructed shares of foreign-born as an instrument, based on the Card (2001) method and described in the appendix 6. This instrument is very effective in these regressions. The partial $R^{2}$ of the first stage regression is 0.25 and the F-test for excluding the instrument is above 100 for each regression. Table 5 reports the 2SLS estimates of the coefficients $\gamma_{E}, \gamma_{w}$, and $\gamma_{r}$. Column I reports those obtained with the panel of 86 cities over 4 census years and column II reports those based on 117 cities over 3 census years. Before commenting on the coefficients in detail let us make two general remarks. First the OLS estimates (not reported but available from the authors upon request) are not far from the 2SLS estimates. They are however somewhat larger, implying

\footnotetext{
${ }^{11}$ Details on data and the construction of variables are reported in the Appendix 6.

${ }^{12}$ In order to control for city composition, the value $\ln \bar{w}_{c t}$ is calculated as the city-specific intercept of a Mincerian regression of log hourly (or yearly) wage of U.S. born workers (in constant 2000 prices) on personal characteristics (years of schooling, experience dummies, a gender dummy, race dummies, and a marital status dummy). The regressions are run separately for each census year. Details are reported in Appendix 6.

${ }^{13}$ The value $\ln \bar{r}_{c t}$ is calculated as the average value of houses occupied by U.S.-born people (in constant 2000 prices) divided by the number of rooms in city $c$ and year $t$. An alternative measure is the gross rental value per room. Details are in the Appendix 6
} 
the potential existence of an upward OLS bias. Second we do not include any controls (besides city and time fixed affects) in the regression to eliminate any endogeneity in the regressor that we cannot solve with an IV strategy. Our previous work (Ottaviano and Peri 2005, forthcoming) introduces a series of potential controls and checks. The interested reader may check that the estimated positive coefficients are rather robust to most controls.

The first row of Table 5 shows the estimated impact of immigration on the employment of native workers, $\gamma_{E}$. This effect is positive but quite imprecisely estimated. No evidence exists that increasing aggregate emigration of U.S.-born workers from cites attracts larger number of immigrants. The impact of immigration on wages (rows 2 and 3) and on the value of housing (rows 4 and 5) of U.S.-born residents is significantly positive. Alternatively we use yearly or hourly wages of U.S.-born workers (rows 2 and 3) and control for individual characteristics in a first-stage regression. The estimates in row 2 and 3 imply that a $1 \%$ increase in the share of foreign-born workers in total employment raises average wage of U.S. workers by between 0.35 to 0.46 percentage points. The last two rows calculate the impact of foreign-born workers on the value of housing for U.S.-born residents. We use gross rents (for leased properties) and values of housing (for owner-occupied ones) as alternative measures of the value of housing. The estimated coefficients imply that an increase of foreign workers by $1 \%$ of the initial employment causes an increase in the value/price of housing for the U.S.-born by 1.1 to 1.6 percentage points. ${ }^{14}$ These estimates imply a strong positive impact from foreign-born workers on city economies, which put upward pressures on wages and housing prices, and attract (or at least do not push away) native workers. Remarkably the average effect from immigrants on U.S. wages (mostly between 0.35 and 0.38 ) is very close to the effect of immigration on the average wages calculated in Table 2 , row 3 , equal to 0.34 . Our production function seems to match quite well the aggregate effects on wages when we estimate them using their cross-city variations. In the next section we also account for the observed elasticities of housing prices and of internal migration.

\section{$4 \quad$ An Open City Model}

\subsection{Description of the Model}

To simulate the reactions of wages, rents and location decisions for U.S.-born workers to foreign immigration, we embed the aggregate production function (1) into a simple model of a small city within an open city system. Specifically, consider a city with land area equal to $T$ inhabited by $L$ workers. To reduce the complexity of the extended set-up, we neglect differences in experience across workers, and focus instead only on differences in education. Accordingly, workers are differentiated into four education groups ( $H S D, H S G, C O D, C O G)$ as well as between home and foreign born $(H$ and $F)$. This produces eight groups, whose supplies are denoted as

\footnotetext{
${ }^{14}$ These estimates are virtually identical to those in Saiz (2003).
} 
in the following matrix:

$\begin{array}{cccc}\text { Skill } & \text { Home } & \text { Foreign } & \text { Total } \\ H S D & H_{H S D} & F_{H S D} & L_{H S D} \\ H S G & H_{H S G} & F_{H S G} & L_{H S G} \\ C O D & H_{C O D} & F_{C O D} & L_{C O D} \\ C O G & H_{C O G} & F_{C O G} & L_{C O G} \\ \text { Total } & H & F & L\end{array}$

All workers share the same preferences which are defined over three goods: the freely tradable good $Y$, non-tradable services $X$, and housing $Z$. The corresponding utility function is:

$$
U=Y^{\alpha} X^{\beta} Z^{1-\alpha-\beta}
$$

with

$$
X=\left[\left(\frac{X_{H}}{\tau_{X H}}\right)^{\frac{\gamma-1}{\gamma}}+\left(\frac{X_{F}}{\tau_{X F}}\right)^{\frac{\gamma-1}{\gamma}}\right]^{\frac{\gamma}{\gamma-1}}
$$

where $Y$ is the consumption of the tradable good and $Z$ is the consumption of housing. Services come in two varieties that are horizontally differentiated in terms of "ethnicity," with the elasticity of substitution equal to $\gamma>1$. The idea we wish to capture is that the ethnic diversity of local services may produce urban amenities. Accordingly, $X_{H}$ and $X_{F}$ denote consumption levels of home and foreign varieties respectively. Sub-utility (20) exhibits a 'love for variety': workers prefer a balanced consumption of both ethnic varieties.

Home-born workers are freely mobile among cities. ${ }^{15}$ They consume and supply labor only in their city of residence. This requires cities to be sufficiently far apart to prevent cross-city commuting. Each worker inelastically supplies one unit of labor to the production of the tradable good $Y$ and one unit of labor to the production of her own ethnic variety of non-tradable services $X$ (this can be considered 'backyard production'). All markets are perfectly competitive. The production of the tradable good $Y$ is identical to the one defined in (5) with the sole simplification that within the labor composite defined in (2) we do not subdivide each education group into experience cells (that is, we let $\theta$ in expression 3 be $\infty$ ). Housing production requires one unit of land per unit of output. Lot-size is normalized to unity so that in the city total housing supply equals $T$. The production of variety $h$ of non-tradable services $X$ requires one unit of labor of type $h$ per unit of output. Hence, $X_{H}=H$ and $X_{F}=F$. What we are trying to capture is the utility-enhancing diversity of restaurants, specialty food shops and entertainment opportunities afforded to a city with more foreign-born residents. For example, Chinese, Italian, and Brazilian restaurants, along with Spanish opera singers, Russian dancers and Ukrainian ice skaters, all provide specific services that simply cannot be replicated by U.S.-born competitors.

\footnotetext{
${ }^{15}$ We assume that the distribution of foreign born is exogenously given, and that a change in their supply is an immigration shock.
} 
Thus, the home and foreign born may complement each other not only in terms of tradable production (see 5) but also in terms of non-tradable consumption (see (19) and (20)). Finally, we call $1 / \tau_{X h}$ the efficiency units of a worker born in $h$ in the production of her group-specific services $X_{h}\left(1 / \tau_{X h}\right.$ can be also interpreted as a quality parameter).

In equilibrium workers maximize utility, firms maximize profits and all markets clear. Since U.S.-born workers are free to move across cities, workers within the same skill group reach the same level of utility everywhere. Similarly, since firms are free to enter and exit, their profits are equal to zero everywhere. As the formal equilibrium conditions are fairly standard, we prefer to relegate them and their derivation to Appendix 7 , and focus instead on the logic of our simulation experiment.

\subsection{Parametrization and Calibration}

Our city is a small-open economy in which U.S.-born workers move in and out in order to equate their indirect utility ('real wage') in the city to the real wage perceived in the rest of the economy. We wish to calibrate this city as the average U.S. city in order to simulate the effects of foreign immigration from 1990 to 2000 on the average wages, rents and location decisions of U.S.-born workers. In so doing, we compare this city equilibrium before and after the migratory shock captured by the change of the supply of foreign-born workers in each of the four education groups $\left(\Delta F_{H S D}, \Delta F_{H S G}, \Delta F_{C O D}, \Delta F_{C O G}\right)$. We model this shock as exogenous to any city-specific event. Variables with a 0 subscript are associated with the pre-shock equilibrium (1990), while a subscript of 1 denotes post-shock values (2000). This is therefore a comparative statics exercise, since we consider what happens to the variables of interest once the new equilibrium is reached. However, in order to understand the mechanisms that drive the migration of workers between the initial shock and the new equilibrium, we also report the "effect on impact" of the immigration of foreign-born, that is, what happens to wages and the values of houses before the migratory response of U.S. citizens takes place.

The initial equilibrium is calibrated on the average U.S. metropolitan area in 1990. We standardize both its initial total employment and its land endowment to 1 . Accordingly, the vector of initial endowments of U.S.-born workers $\left(H_{H S D 0}, H_{H S G 0}, H_{C O D 0}, H_{C O G 0}\right)$ is $(0.084,0.257,0.294,0.264)$ while the vector of the initial endowments of foreign-born workers $\left(F_{H S D 0}, F_{H S G 0}, F_{C O D 0}, F_{C O G 0}\right)$ is $(0.031,0.02,0.024,0.029)$. This implies that foreign-born workers as a whole equal $10.6 \%$ of U.S. employment, which corresponds to the aggregate figures for metropolitan areas in the year 1990. Their distribution was unequal across skill groups as they were over-represented among the low skilled ( $26 \%$ of high-school dropouts), under-represented among the medium skilled ( $7.5 \%$ of high school graduates and college dropouts) and proportionally represented among the high skilled (10\% of college graduates).

The magnitude of the immigration shock during the 1990s was quite large, as the foreign born population 
almost doubled in the U.S., going from $7 \%$ to $13.5 \%$ of total employment. Our experiment maintains the employment and distribution of U.S.-born workers as in 1990, and increases foreign-born workers by the amount experienced by the average U.S. metropolitan area during the 1990-2000 period. The resulting shock is $\left(\Delta F_{H S D}\right.$, $\left.\Delta F_{H S G}, \Delta F_{C O D}, \Delta F_{C O D}\right)=(1.9 \%, 1.5 \%, 1.5 \%, 3.0 \%)$. The total increase in foreign employment is therefore $8 \%$ of initial U.S. employment. Notice that the values used for both the initial conditions and for the shock are exactly the same as those used in the calculations in section 2.4 .

We obtain some of the parameter values required to simulate the model either directly from the literature or from simple calculations. Others are instead estimated. We also provide several robustness checks of our simulation results using different values for these parameters. The parameters of the utility function have been obtained using the share of household expenditures on housing services to obtain $(1-\alpha-\beta)$ and on local food and entertainment services $(X)$ to obtain $\beta$. These data are from the Consumer Expenditure Survey, available at Bureau of Labor Statistics (2005). The share of expenditures in housing services for the 19992002 period was slightly larger than 0.20 . We choose $1-\alpha-\beta=0.20$ as a base-value, and test the effect of assuming $1-\alpha-\beta=0.25$. As for the share of expenditures on local service $X$, we include expenditures for food in restaurants, food in specialty shops, and entertainment. This share ranges between 0.15 and 0.20 of the expenditures of the average U.S. household. We choose $\beta=0.2$ as base-value and also test the effect of the assumption $\beta=0.15$. As for the substitutability between the non-tradable services provided by the U.S. and foreign born, we assume a conservatively high elasticity $(6-7)$. Considering that the median elasticity of substitution between goods within five-digit SITC sectors has been estimated by Weinstein and Broda (2004) as 4.7 , our values certainly fall on the high side. ${ }^{16}$ Our choice of using a high elasticity limits the importance of ethnic diversity in making a location attractive, therefore biasing the results against us.

In the production of the traded good (5) we assume an elasticity between skill groups of $\delta=1.8$ (experimenting also with 2), which is consistent with our choice in section 2. The relative efficiencies of the factors $\left(1 / \tau_{k}\right)$ are chosen to match the national wage premia between education groups, given their relative supplies and the elasticity of substitution $\delta$. Standardizing the efficiency of $H S D$ workers $\left(\tau_{H S D}=1\right)$ we can obtain the other values by using the formula: $\ln \left(\frac{\tau_{H S D}}{\tau_{k}}\right)=\frac{\delta}{\delta-1}\left[\ln \left(\frac{w_{k}}{w_{H S D}}\right)+\frac{1}{\delta} \ln \left(\frac{E_{k}}{E_{H S D}}\right)\right]$, where $w_{k}$ is the average national wage for workers of education $k$, and $E_{k}$ is the total supply of workers of education group $k$. The relative efficiency of the foreign born to U.S.-born both in any skill group and in the production of local services has been set equal to 1 .

After the exogenous immigration shock, the new equilibrium is established when the supply of U.S.-born workers in the city is adjusted so that the utility they enjoy in the city is the same they would enjoy anywhere else. Under the small economy assumption, the utility levels for natives who reside elsewhere are kept constant

\footnotetext{
${ }^{16}$ For instance a narrow SITC-5 digits category such as "cheese" has an elasticity of 4.5 among its varieties.
} 
at their initial values $\left(\bar{V}_{H S D}, \bar{V}_{H S D}, \bar{V}_{C O D}, \bar{V}_{C O G}\right)$. These of course are unobservable, and are calculated as the implicit values that make the equilibrium supply of the U.S.-born predicted by the model match their actual supply in $1990\left(H_{H S D 0}, H_{H S G 0}, H_{C O D 0}, H_{C O G 0}\right)$ for the given initial distribution of foreign-born residents $\left(F_{H S D 0}, F_{H S G 0}, F_{C O D 0}, F_{C O G 0}\right) .{ }^{17}$ This completes the parametrization of the model. In the next section we describe the results of this simulation.

\subsection{Simulation Results}

Table 6 summarizes the results of our simulations. Maintaining the common average shock that mirrors the actual increase in foreign-born workers during the 1990s, the seven columns correspond to simulations for different combinations of parameter values. While we are mainly interested in the long-run (equilibrium) effects in order to match our estimated effects across decades, the first two rows (below the parameters values) report the short-run effects from immigration on the average wages and housing values for U.S.-born workers. The following three rows report the effects on the average variables for U.S.-born individuals (i.e., the percentage change in average wage, the percentage change in the value of housing, and in- or out-migration), all calculated in the new 'long-run' equilibrium, after internal migration takes place and the new equilibrium is reached. The last three rows report the implied elasticities of wages, rents and internal migration from the inflow of foreign-born, and are directly comparable with the estimated coefficients $\gamma_{w}, \gamma_{r}, \gamma_{E}$ reported in Table 5 .

The first column of Table 6 (specification I) shows results from the main simulation that uses the baseline choices for the parameters as described in the previous section. In particular note that the 'preferred' values for the parameters $\sigma_{k}$ (equal to $6,7,7,3$ ) are used. Specification II employs the parameter values for $\sigma_{k}$ 's that are closer to the point estimates of Table 1 (equal to $7,10,10,4$ ). The remarkable feature of these two specifications is that they generate long-run elasticities of average wages and rents that match very closely the estimated range of elasticities in Table 5. In particular, $\gamma_{w}$ is simulated to be between 0.35 and 0.42 while $\gamma_{r}$ is between 1.18 and 1.58. The corresponding estimated ranges are $(0.35-0.46)$ and $(1.11-1.61)$ for $\gamma_{w}$ and $\gamma_{r}$ respectively. The parameter $\gamma_{E}$ is more variable and not far from 0 . Its variability in the simulation derives from the fact that different skill groups have different migration behavior (native $H S D$ always move out while the other groups move in) so that the overall effect is uncertain. This has a correspondence, however, in the very large variability and imprecision of the estimated effect that was often not significantly different from 0 in Table 5. Specification III is shown purely for reference as it assumes very high values for the elasticity of substitution between U.S. and foreign born (not supported by the evidence). It is clear that the large positive effect on average wages and rents depends heavily on the imperfect substitutability between the U.S. and foreign born. If, as in this specification, natives and foreigners are close to perfect substitutes, then the effect on wages

\footnotetext{
${ }^{17}$ See appendix 7 for details on the calibration of these initial utility levels.
} 
and rents is smaller, and is accompanied by a net out-migration of U.S.-born workers.

Specifications IV to VII show the robustness of the simulated elasticities (especially $\gamma_{w}$ and $\gamma_{r}$ ) to changes in the other parameters. Specification IV increases the elasticity of substitution between local services (produced by U.S. and foreign born workers) to 7; specification $\mathrm{V}$ increases the share of total expenditures on housing services to $25 \%$; specification VI reduces the share of spending on food-entertainment to $15 \%$; and specification VII increases the elasticity of substitution between schooling groups to 2. Each specification produces values of $\gamma_{w}$ and $\gamma_{r}$ within our estimated range (Table 5) and values of $\gamma_{E}$ that are either positive or very close to 0, confirming that there seem to be no strong tendencies for U.S.-born residents to leave cities that experience migration.

Thus, for plausible parameter values, our simple (and quite standard) model finds significant positive effects of immigration on the average wages and rents of U.S.-born workers. Quite remarkably, the magnitude of this effect is equal to what our IV estimates produce across U.S. cities.

\section{Conclusion}

Along with goods and capital, the increased movement of people across countries has been a prominent feature of the last few decades. While in general economists are among the staunchest supporters of freer trade and capital movement, they have primarily argued that migration hurts U.S. native workers, in particular those with low skills. Whereas it is hard to deny that in any reasonable model, the relative increase of low skilled workers will cause a decrease in their relative wage, this study is interested primarily in determining the overall (average) effect of immigration, aggregating across groups of U.S.-born workers. It turns out both empirically and theoretically that immigration, as we have known it during the nineties, had a sizeable beneficial effect on the wages of U.S.-born workers. For a flow of migrants that increases total employment by $10 \%$ and a skill distribution that mirrors the one observed in the nineties, U.S.-born workers experience a 3-4 percentage point increase in their wages. This results because U.S. and foreign-born workers are not perfectly substitutable, even when they have similar observable skills. Workers born, raised and partly educated in foreign environments are not identical to workers born and raised in the U.S. This set of differences that we might label 'diversity' is the basis for the gains from immigration that accrue to U.S.-born workers. Even a small degree of difference, captured by a relatively high elasticity of substitution between U.S. and foreign-born workers (between 4 and 7), is enough to generate the average wage gains that we estimate from U.S. metropolitan data using a reducedform equation. We believe that sharpening our understanding of the complementarities and substitutability between the U.S. and Foreign born in different sectors and skills, along with using an aggregate production function approach, are crucial steps in quantifying the benefits of immigration to the U.S. economy. We hope that this article may encourage a line of research into such "gains" from immigration, rooted in production 
complementarities (between workers and with physical capital) that may account for these important and thus far neglected effects from immigration. 


\section{References}

[1] Angrist, Joshua (1995) "The Economic Returns to Schooling in the West Bank and Gaza Strip," American Economic Review 85 (1995), 1065-1087.

[2] Altonji, Joseph J. and David Card (1991) "The effects of Immigration on the Labor Market Outcomes of Less-Skilled Natives "in John M. Abowd and Richard Freeman eds, Immigration, Trade and the Labor Market, Chicago, the University of Chicago Press.

[3] Borjas, George J. (1987) "Immigrant, Minorities and Labor Market Competition" Industrial and Labor Relations Review, 40, 382-392.

[4] Borjas, George J. (1994) "The Economics of Immigration" Journal of Economic Literature 32, 1667-1717.

[5] Borjas, George J. (1995) "The Economic Benefits from Immigration" Journal of Economics Perspectives, $9(2), 3-22$.

[6] Borjas, George J. (1999) "Heaven's Door" Princeton University Press, Princeton and Oxford, 1999.

[7] Borjas, George J. (2003) "The Labor Demand Curve is Downward Sloping: Reexamining the Impact of Immigration on the Labor Market" Quarterly Journal of Economics, CXVIII (4), 1335-1374.

[8] Borjas, George J., Freeman, Richard and Katz, Larry (1997) "How Much do Immigration and Trade Affect Labor Market Outcomes?" Brookings Papers on Economic Activity, 1997 (1), 1-90

[9] Bureau of Labor Statistics (2005) " The Consumer Expenditure Survey" year 1999-2002, http://www.bls.gov/cex/home.htm\#tables.

[10] Butcher, Katrin C. and Card, David (1991) "Immigration and Wages: Evidence from the 1980s" American Economic Review, Papers and Proceedings, 81 (2), 292-296.

[11] Card, David (1990) "The Impact of the Mariel Boatlift on the Miami Labor Market" Industrial and Labor Relation Review, XLIII, 245-257.

[12] Card, David (2001) "Immigrant Inflows, Native Outflows, and the Local labor Market Impacts of Higher Immigration" Journal of Labor Economics, XIX (2001), 22-64.

[13] Card, David and Di Nardo, John (2000) "Do Immigrants Inflow Lead to Native Outflows?" NBER Working Paper n. 7578.

[14] Card, David and Lemieux, Thomas (2001) "Can Falling Supply Explain the Rising Returns to College for Younger Men? A Cohort Based Analysis" Quarterly Journal of Economics, Vol. CXVI, pag. 705-746. 
[15] Ciccone, Antonio and Peri, Giovanni (2005) "Long-Run Substitutability between More and Less Educated Workers: Evidence from US States 1950-1990" Review of Economics and Statistics, Vol. 87, Issue 4.

[16] Fallon, P.R. and Layard P.R.G. (1975), "Capital-Skill Complementarity, Income Distribution, and Output Accounting," Journal of Political Economy 83, 279-302.

[17] Filer, Randy (1992) "The Impact of Immigrant Arrivals on Migratory Patterns of Native Workers" in Immigration and the Work Force: Economic Consequences for the United States and Source Areas edited by Borjas and Freeman. University of Chicago Press, Chicago.

[18] Frey, William H.(1995) "Immigration Impact on Internal Migration of the Poor: 1990 Census Evidence from US States" International Journal of Population Geography 1, 51-67.

[19] Grossman, Jean B. (1982) "The Substitutability of Natives and Immigrants in Production" Review of Economics and Statistics, 64, 596-603.

[20] Hamermesh, Daniel (1993), Labor Demand, (Princeton, New Jersey: Princeton University Press.

[21] Johnson, Gary. (1970), "The Demand for Labor by Educational Category," Southern Economic Journal, 37, 190-203.

[22] Katz, Larry and Murphy, Kevin (1992) "Change in Relative Wages 1963-1987: Supply and Demand Factors," Quarterly Journal of Economics 107, 35-78.

[23] Lewis, Ethan (2003) "Local Open Economies within the US. How do Industries respond to Immigration?" Federal Reserve Bank of Philadelphia, Working Paper 04-1.

[24] National Research Council (1997) "The New Americans: Economic, Demographic, and Fiscal Effects of Immigration" National Academy Press, Washington D.C..

[25] Ottaviano, Gianmarco I.P. and Peri Giovanni (2005) "The Economic Value of Cultural Diversity: Evidence from U.S. cities" Journal of Economic Geography, Advance Access published on June 22, 2005, DOE $10.1093 / \mathrm{jeg} / \mathrm{lbi002}$.

[26] Ottaviano, Gianmarco I.P. and Peri Giovanni (forthcoming) "Cities and Cultures" Journal of Urban Economics, forthcoming

[27] Park, Jin Huem (1994) "Estimation of Sheepskin Effects and Returns to Schooling Using the Old and New CPS Measures of Educational Attainment", Princeton University Industrial Relation Section, Working Paper No. 338.

[28] Ramsey, Frank.P. (1928) "A Mathematical Theory of Saving" Economic Journal, 38, 543-559. 
[29] Ruud, Paul A. (2000), An Introduction to Classical Econometric Theory, Oxford University Press, Oxford.

[30] Ruggles Steven, Matthew Sobek, Trent Alexander, Catherine A. Fitch, Ronald Goeken, Patricia Kelly Hall, Miriam King, and Chad Ronnander (2005). Integrated Public Use Microdata Series: Version 3.0 [Machine-readable database]. Minneapolis, MN: Minnesota Population Center [producer and distributor], 2004. http://www.ipums.org.

[31] Saiz, Albert (2003) "Room in the Kitchen for the Melting Pot: Immigration and Rental Prices." Review of Economics and Statistics, 85, 502-521.

[32] Solow, Robert (1956). "A Contribution to the Theory of Economic Growth," Quarterly Journal of Economics, 70, pp. 65-94.

[33] Weinstein, David and Broda, Christian (2004) "Globalizatoin and the Gains from Variety" NBER Working Paper n. 10314. 


\section{Appendix: Data and Definition of the Variables}

\subsection{Construction of Average Wage and Average House Values}

The value of $\ln \bar{w}_{c t}$ used in Section 3.3 to calculate $\Delta \ln \bar{w}_{c t}$ is obtained separately for each census year as the MSA-specific intercept of the following Mincerian regression on individual data, after having separated U.S.-born individuals from individuals that were born abroad but have since become U.S. citizens:

$$
\ln w_{i c t}=\ln \bar{w}_{c t}+\alpha(\text { School })_{i}+\beta(\text { Experience })_{i}+\gamma(\text { Sex })_{i}+\delta(\text { Race })_{i}+\theta(\text { Marital })_{i}+\varepsilon_{i c t}
$$

The variable $\ln \bar{w}_{c t}$ captures 84 (or in the 1970-1990 sample 117) MSA-specific dummies. The variable School represents four dummies corresponding to the following groups: High School Dropouts, High School Graduates, College Dropouts and College Graduates. This variable is constructed using the variable "highest grade attended" (HIGRADEG) for the 1970 and 1980 censuses, and the categorical variable (defined as educ99 in the IPUMS files). This variable has been converted into years of schooling using the correspondence developed in Park (1994). The variable Experience represents eight dummies for five-year groups of experience between 0 and 40 years. It is calculated as potential experience, namely, Age - Years of Schooling - 6. The variable Sex is a dummy equal to 1 when the worker is a woman and 0 otherwise. The variable Race stand for five dummies corresponding to White, Black, Hispanic, Native and Asian. The variable Marital identifies three dummies corresponding to being single, being married or being divorced. The omitted dummies are such that the intercept captures the value for the reference group of high school graduates with 15-20 years of experience, white, male and married. When we use hourly wages as the measure of $w_{i c t}$ we obtain it by dividing the variable "wage and salary income" (previously converted into 2000 USA $\$$ using the CPI deflator) by the variable weeks worked last year and then by "hours worked last week" (categorized in the 1970 and 1980 censuses) or by "hours usually worked per week" (categorized in the 1990 and 2000 censuses). We selected people who were in the labor force, worked at least one week during the census year and received a non-zero salary.

The value of $\ln \bar{r}_{c t}$ used in Section 3.3 to calculate $\Delta \ln \bar{r}_{c t}$ is also obtained separately for each census year as the average by MSA of monthly gross rent (RENTGRS) converted into 2000 US $\$$ using the CPI deflator, or of the value of the house (VALUEH), also converted into 2000 US \$. Each value has been divided by the number of rooms (ROOMS) in the house to standardize for the size of the house and obtain a value per room, comparable across cities. Only U.S.-born heads of households have been included in the sample.

\subsection{Construction of the Instrument}

We first define 56 countries (or group of countries) of origin of foreign-born workers that can be tracked consistently from the 1970 census to the 2000 census. Together they accounted for more than $98 \%$ of all foreign- 
born. These countries are: Canada, Atlantic Islands, Mexico, Central America, Cuba, West Indies, SOUTH AMERICA, Denmark, Finland, Iceland, Norway, Sweden, England, Scotland, Wales, Ireland, Belgium, France, Luxembourg, Netherlands, Switzerland, Albania, Greece, Italy, Portugal, Spain, Austria, Bulgaria, Czechoslovakia, Germany, Hungary, Poland, Romania, Yugoslavia, Estonia, Latvia, Lithuania,Russia, Rest of Europe, China, Japan, Korea, Philippines, Vietnam, India, Iran, Israel/Palestine, Jordan, Lebanon, Syria,Turkey, Rest of Asia, AFRICA, Australia and New Zealand, Pacific Islands, Abroad (unknown). From the 1970 census we calculate the working population of skill group $k$ (for $k=H S D, H S G, C O D, C O G$ ) in Metropolitan Area $c$ (for $c=1, \ldots 117)$ from each of these nations and call it $L_{n k c 1970}$. Using the overall Census (1970-2000) we calculate the overall growth rate of each skill by nation group ( $k$ by $n=1, \ldots 56,57)$ for the entire U.S.. Foreign-born workers in different skill groups grew because of different amounts of immigrations from different nations of origin, as well as different migration rates across skill groups. For each decade $t=1970,1980,1990$ we define the growth rate of a nation-skill group during that decade as $g_{n k t}=\left(L_{n k t+10}-L_{n k t}\right) / L_{n k t}$. We apply these nationskill growth rates for each decade to the initial population in a skill-nationality group for each city $c$ to obtain an

imputed skill-nationality population of city $c$ over the decades: $\widehat{L}_{n k c t+10}=L_{n k c 1970}\left(1+g_{n k t}\right)$ where the "hat" indicates that the value is imputed. Finally using these imputed populations we can calculate the imputed shares of foreign born in each city and skill group for each census year (1980-2000). As the imputed variables are constructed using only national averages and the initial distribution of foreign-born, city-specific shocks that occurred during the period (1970-2000) which affected actual migration into a city should be uncorrelated with them.

\section{Appendix: Equilibrium of the City Model}

Let us define $w_{k h}$ as the wage per worker born in $h$ with skill level $k, p_{Y}$ the price per unit of tradable good $Y$, $p_{X h}$ the price per unit of non-tradable service $h$, and $r$ the land rent. Also define $\Gamma \equiv\{H S D, H S G, C O D, C O G\}$ as the set of education levels and $\Theta \equiv\{H, F\}$ as the set of birthplaces.

\subsection{Equilibrium Conditions}

If we call $\bar{w}$ the vector of $w_{k h}$ 's and $\bar{E}$ the associated vector of labor endowments, then aggregate income can be written as:

$$
I=\bar{w}^{\prime} \bar{E}+p_{X H} X_{H}+p_{X F} X_{F}+r T
$$

Utility maximization and market clearing in all sectors imply:

$$
I=\frac{\bar{w}^{\prime} \bar{E}}{\alpha}
$$




$$
r T=\frac{1-\alpha-\beta}{\alpha} \bar{w}^{\prime} \bar{E}
$$

Given (5), profit maximization requires:

$$
p_{Y} \widehat{A}=P_{C}
$$

where $\widehat{A}$ is a constant defined in Section 2 and:

$$
\begin{gathered}
P_{C}=\left(\sum_{k \in \Gamma} \phi_{k} P_{k}^{1-\delta}\right)^{\frac{1}{1-\delta}} \\
\tau_{k} P_{k}=\left[\phi_{k H}\left(w_{k H}\right)^{1-\sigma_{k}}+\phi_{k F}\left(w_{k F}\right)^{1-\sigma_{k}}\right]^{\frac{1}{1-\sigma_{k}}}, k \in \Gamma
\end{gathered}
$$

are the price indices associated with the quantity indices $C$ and $C_{k} / \tau_{k}$ respectively, $\phi_{k} \equiv\left(\tau_{k}\right)^{1-\delta}$ and $\phi_{k h} \equiv$ $\left(\tau_{k h}\right)^{1-\sigma_{k}}$.

The exact aggregation properties of the above quantity and price indices ensure that

$$
P_{C} C=\bar{w}^{\prime} \bar{E}
$$

as well as $\sum_{k \in \Gamma} P_{k} C_{k}=P_{C} C$ and $\sum_{h \in \Theta} w_{k h} k_{h}=P_{k} C_{k}$. Exploiting these properties, profit maximization also implies:

$$
\begin{gathered}
P_{k} C_{k}=\phi_{k}\left(\frac{P_{k}}{P_{C}}\right)^{1-\delta} P_{C} C \\
w_{k h} k_{h}=\phi_{k h}\left(\frac{w_{k h}}{P_{k}}\right)^{1-\sigma_{k}} P_{k} C_{k}
\end{gathered}
$$

for all $k \in \Gamma$ and $h \in \Theta$. These expressions can be easily manipulated to produce:

$$
\begin{gathered}
\phi_{k}\left(\frac{P_{k}}{P_{C}}\right)^{1-\delta}=\frac{\phi_{k}^{\frac{1}{\delta}} C_{k}^{\frac{\delta-1}{\delta}}}{\sum_{k \in \Gamma} \phi_{k}^{\frac{1}{\delta}} C_{k}^{\frac{\delta-1}{\delta}}}=\phi_{k}^{\frac{1}{\delta}}\left(\frac{C_{k}}{C}\right)^{\frac{\delta-1}{\delta}} \\
\phi_{k h}\left(\frac{w_{k h}}{P_{k}}\right)^{1-\sigma_{k}}=\frac{\phi_{k h}^{\frac{1}{\sigma_{k}}} k_{h}^{\frac{\sigma_{k}-1}{\sigma_{k}}}}{\phi_{k H}^{\frac{1}{\sigma_{k}}} k_{H}^{\frac{\sigma_{k}-1}{\sigma_{k}}}+\phi_{k F}^{\frac{1}{\sigma_{k}}} k_{F}^{\frac{\sigma_{k}-1}{\sigma_{k}}}}=\phi_{k h}^{\frac{1}{\sigma_{k}}}\left(\frac{k_{h}}{C_{k}}\right)^{\frac{\sigma_{k}-1}{\sigma_{k}}}
\end{gathered}
$$

where $\sigma_{k}$ is the elasticity of substitution between U.S. and foreign born workers within skill group $k$.

Finally, we need to characterize the equilibrium prices of non-tradable services. To do this, we observe that for utility we can exploit the same aggregation properties we used for tradable production. Specifically:

$$
p_{X h} h=\frac{\phi_{X h}^{\frac{1}{\gamma}} h^{\frac{\gamma-1}{\gamma}}}{\phi_{X}^{\frac{1}{\gamma}} H^{\frac{\gamma-1}{\gamma}}+\phi_{X}^{\frac{1}{\gamma}} F^{\frac{\gamma-1}{\gamma}}} \beta I
$$


for $h \in \Theta$.

\subsection{Labor Market Clearing}

We can represent the equilibrium as the intersection of labor demand and supply curves as follows. Demand for labor of skill group $k$ and ethnic group $h$ can be derived by considering (26), (25), (27), (28), and (24). This gives:

$$
w_{k h}=p_{Y} \cdot C^{\frac{1}{\delta}} \cdot \phi_{k h}^{\frac{1}{\sigma_{k}}}\left(h_{k}\right)^{-\frac{1}{\sigma_{k}}} \cdot \phi_{k}^{\frac{1}{\delta}}\left(C_{k}\right)^{-\frac{\sigma_{k}-\delta}{\delta \sigma_{k}}}
$$

which depicts the (inverse) demand for workers born in $h$ with skill level $k$ as a negative relationship between $w_{k h}$ and $k_{h}$.

At the free-mobility spatial equilibrium a worker must be indifferent about her location irrespective of her birthplace or skill level. This is the case if she achieves the same level of indirect utility $\bar{V}_{k h}$ in all cities. Given the utility function (19) this requires

$$
w_{k h}=\bar{V}_{k h} p_{Y}^{\alpha} P_{X}^{\beta} r^{1-\alpha-\beta}
$$

where

$$
P_{X}=\left[\phi_{X H}\left(p_{X H}\right)^{1-\gamma}+\phi_{X F}\left(p_{X F}\right)^{1-\gamma}\right]^{\frac{1}{1-\gamma}}
$$

is the exact price index associated with (20) such that $P_{X} X=\beta I$. Thus, by (21) and (22), we have

$$
w_{k h}=\bar{V}_{k h} p_{Y}^{\alpha} P_{X}^{\beta} r^{1-\alpha-\beta}=\bar{V}_{k h} p_{Y}^{\alpha}\left(\frac{\beta}{X}\right)^{\beta}\left(\frac{1-\alpha-\beta}{T}\right)^{1-\alpha-\beta}\left(\frac{\bar{w}^{\prime} \bar{E}}{\alpha}\right)^{1-\alpha}
$$

which, by (24) and (23), can be rewritten as:

$$
w_{k h}=p_{Y} \cdot \bar{V}_{k h} \cdot(\widehat{A})^{1-\alpha} \cdot B \cdot \frac{(C)^{1-\alpha}}{(X)^{\beta}(T)^{1-\alpha-\beta}}
$$

where $B \equiv(1 / \alpha)^{1-\alpha}(\beta)^{\beta}(1-\alpha-\beta)^{1-\alpha-\beta}$. Given the definition of the composite $C$, (32) depicts the (inverse) supply of workers born in $h$ with skill level $k$ as a positive relationship between $w_{k h}$ and $k_{h}$. With $k \in \Gamma$ and $h \in \Theta,(30)$ and (32) generate a system of eight demands and eight supplies for foreign- and home-born labor. In the solution we choose good $Y$ as numeràire $\left(p_{Y}=1\right)$. 


\subsection{Further Details on Calibration and Simulation}

We find the values of $\bar{V}_{k h} \cdot(\widehat{A})^{1-\alpha}$ by assuming that the endowments of labor across skill and birthplace groups in 1990 correspond to the equilibrium allocations predicted by the model. Accordingly, the 16-dimensional system (30)-(32) can be solved in the following sixteen unknowns: eight wages $w_{k h}$ and eight 'adjusted' indirect utilities $\bar{V}_{k h} \cdot(\widehat{A})^{1-\alpha}$. The latter are held constant in all simulations.

The changes in foreign-born labor endowments from 1990 to 2000 are taken as exogenous. In evaluating the effects on impact, we also take U.S.-born labor endowments as given. With fixed labor supplies, we are left with eight labor demands (30), which can be solved for eight wages. The final adjustment requires U.S.-born workers to re-optimize in terms of location, taking into account exogenous foreign-born migration. This requires us to add four U.S.-born labor supplies to the eight labor demands. The solution of this 12-dimensional system are eight equilibrium wages and four equilibrium quantities for U.S.-born workers. 
Figures and Tables

Figure 1

Percentage of Foreign-Born in US Population

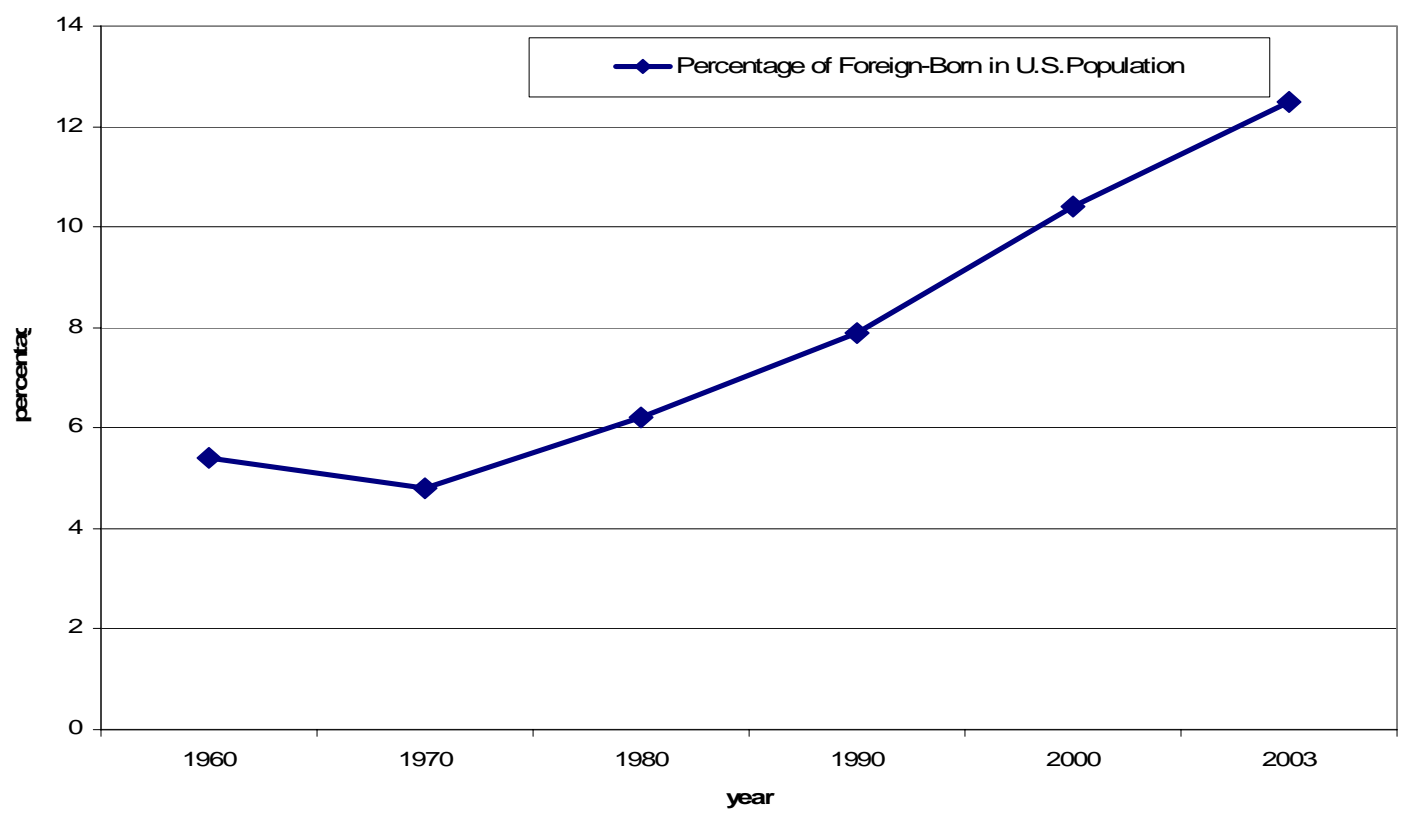

Figure 2

Change in Wage of US born and Change in Share of Foreign Born: 86 Metropolitan Areas, 1970-2000

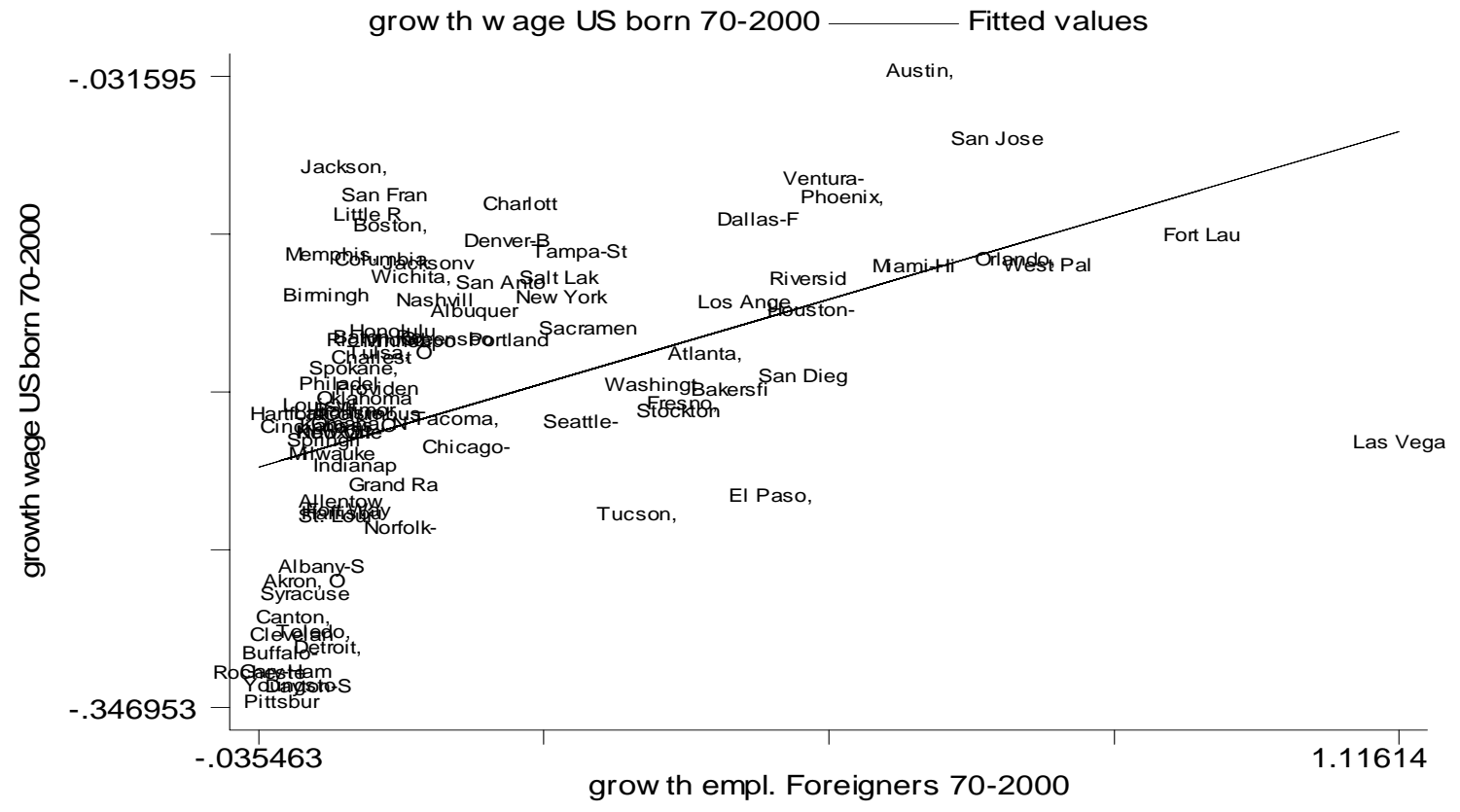




\section{Figure 3}

Change in Rent of US born and Change in Share of Foreign Born: 86 Metropolitan Areas, 1970-2000

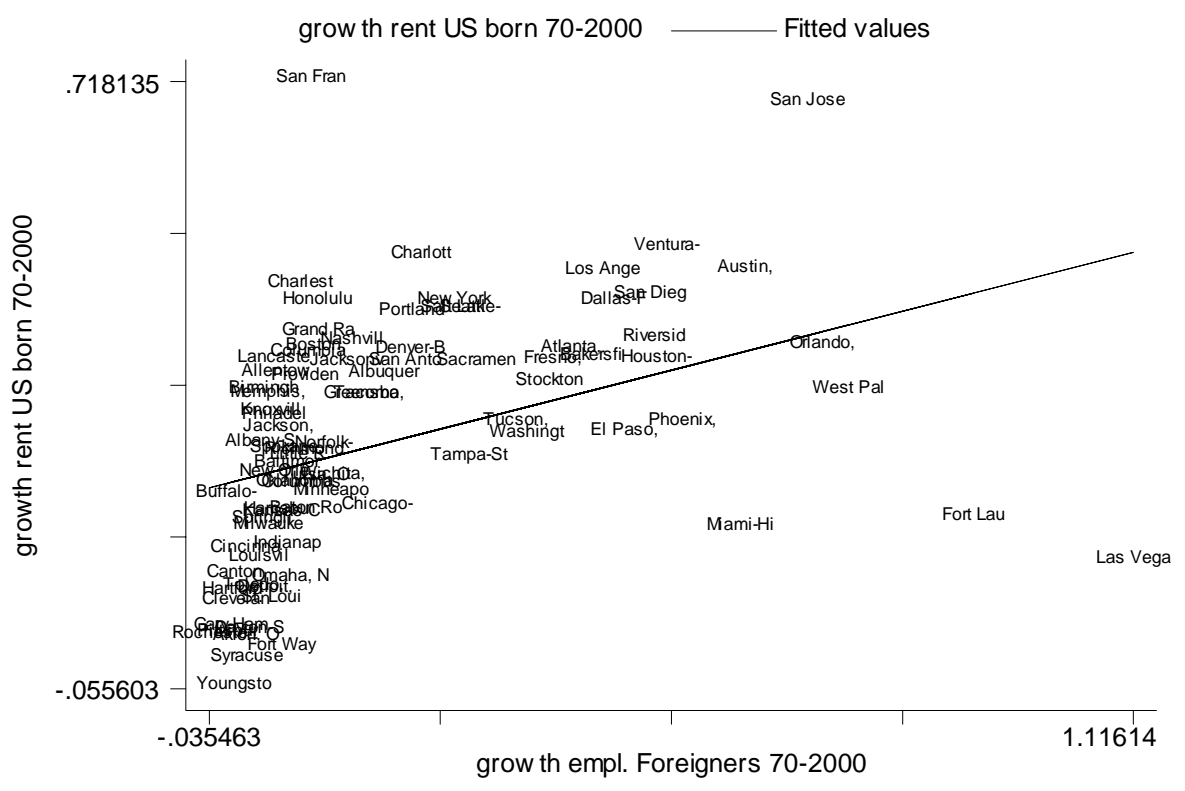

Figure 4

Change in Employment of US born and Change in Share of Foreign Born: 86 Metropolitan Areas, 1970-2000

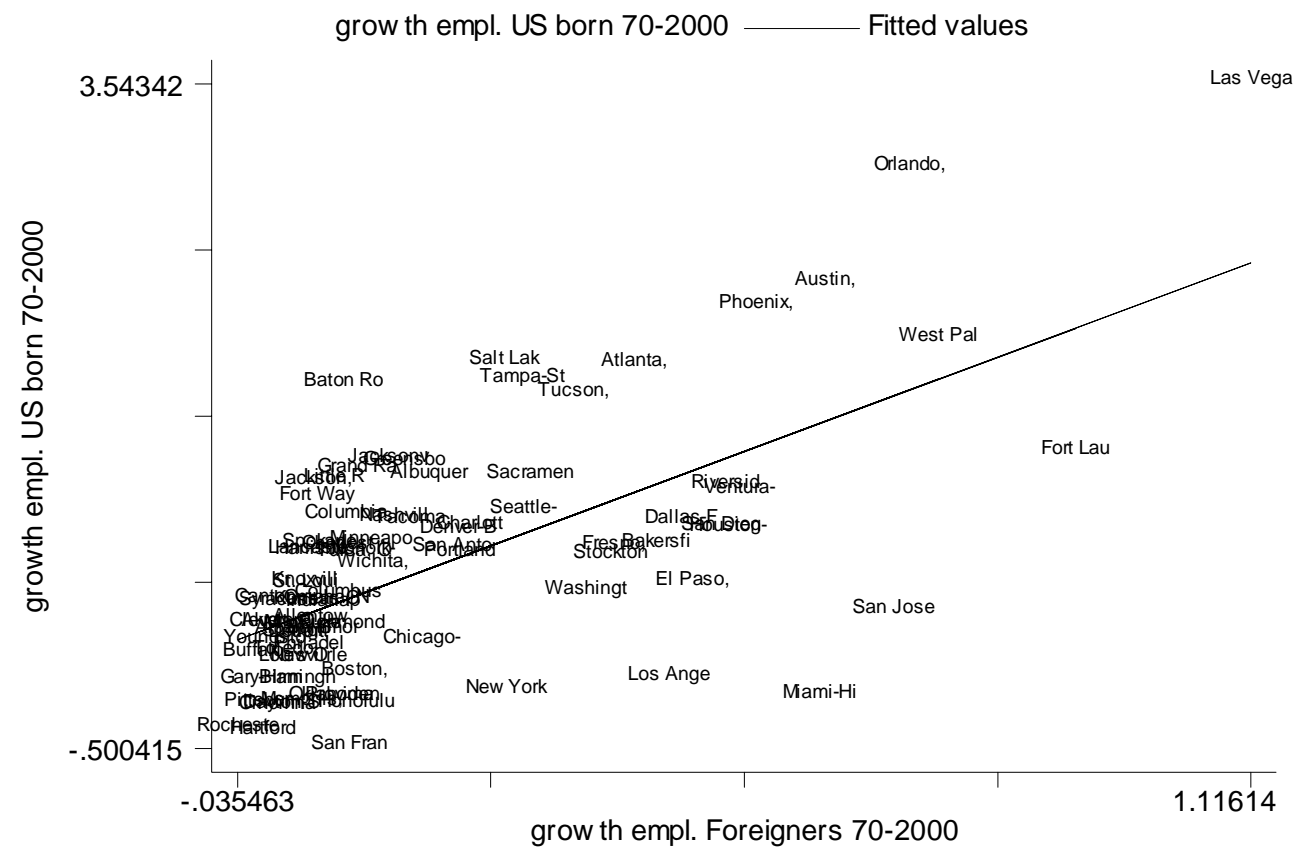


Table 1

\section{Elasticity of Substitution between US-Born and Foreign-Born Workers within the Same Education-Experience Group}

\begin{tabular}{lll} 
Specification & $\begin{array}{c}\text { Imposing same elasticity } \\
\text { across different education } \\
\text { groups }\end{array}$ & $\begin{array}{l}\text { Allowing different } \\
\text { elasticity for each } \\
\text { education group }\end{array}$ \\
\hline$\sigma_{H S D}$ & $7.7^{* *}$ & $7.10^{* *}$ \\
& $(1.77)$ & $(1.05)$ \\
$\sigma_{H S G}$ & $7.7^{* *}$ & $10.1^{* *}$ \\
& $(1.77)$ & $(3.02)$ \\
$\sigma_{C O D}$ & $7.7^{* *}$ & 16.6 \\
& $(1.77)$ & $(11.1)$ \\
$\sigma_{C O G}$ & $7.7^{* *}$ & $4.21^{* *}$ \\
& $(1.77)$ & $(0.66)$ \\
\hline Experience by school & YES & YES \\
effects & & YES \\
\hline Year b y school effects & YES & YES \\
\hline Year by Experience & YES & Log of foreign immigrants \\
Effects & & in each skill group \\
\hline Instruments: & Log of foreign immigrants & 128 \\
\hline Observations & in each skill group & \\
\hline
\end{tabular}

Notes: The parameters $-\left(1 / \sigma_{\mathrm{k}}\right)$ are estimated from the regression of relative wages (foreignborn/US born) on relative supply (foreign-born/US born) for 32 education-experience groups over four census years. The method of estimation is 2SLS. We compute $\sigma_{\mathrm{k}}$ and its standard error using the delta-method. Estimates in each column corresponds to a separate regression.

Heteroscedasticity robust standard error in parenthesis $*, * *$ significantly different from 0 at the $5 \%, 1 \%$ level. 
Table 2

Calculated Effects of Immigration (1990-2000) on Wages of US-born Using the CES Function.

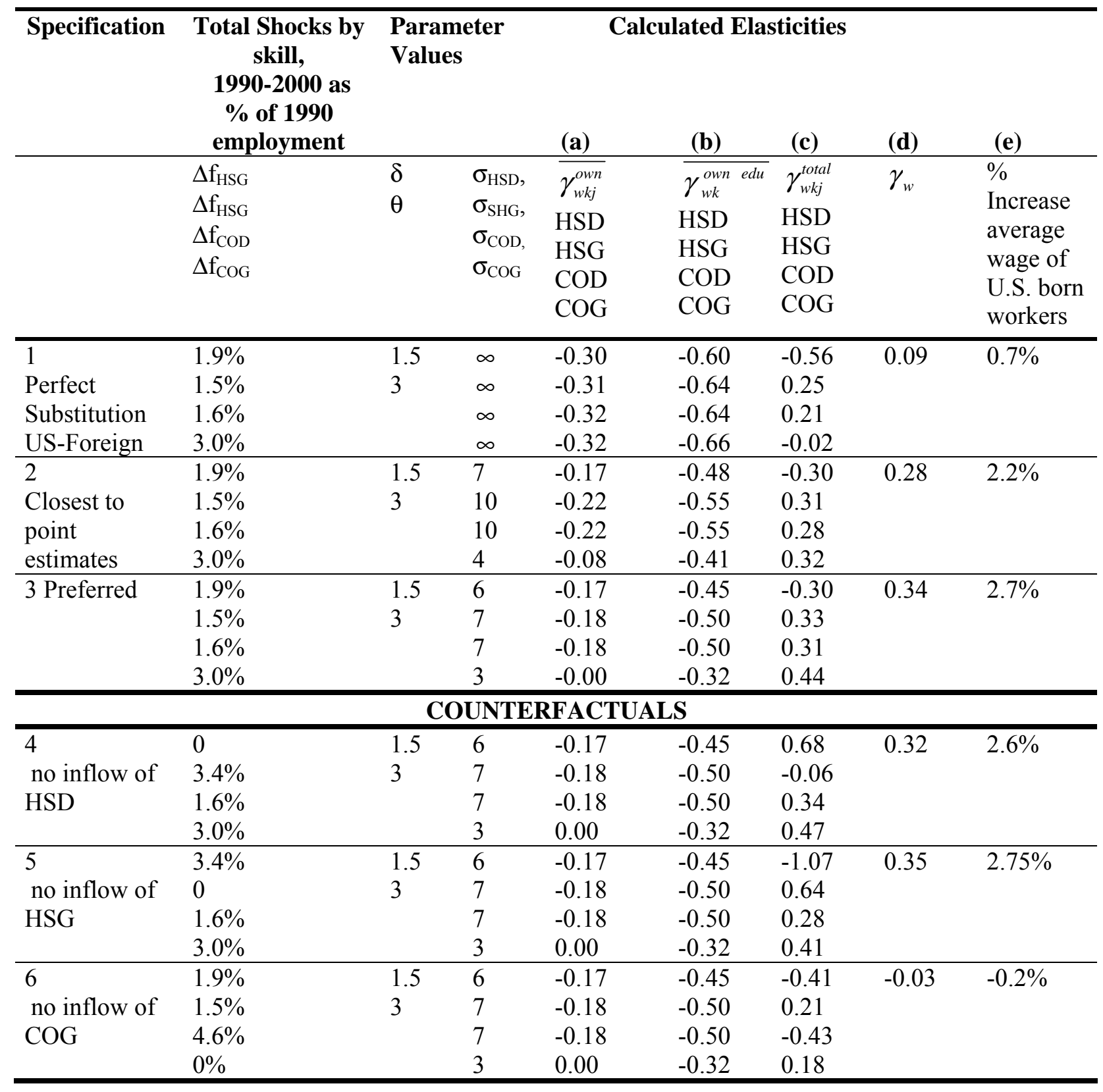

Notes: The Values of $\overline{\gamma_{w k j}^{\text {own }}}, \overline{\gamma_{w k}^{\text {own edu }}}, \gamma_{w k j}^{\text {total }}, \gamma_{w}$ are obtained using the formulas derived in the text. The initial composition of US-born and Foreign-born in each of the skill group replicates the composition of year 1990, as obtained from the IPUMS Census data. The inflows of foreign-born by educationexperience group are calculated from the IPUMS 1990-2000 data. The elasticities $\delta$ and $\theta$ are taken from the literature: Katz and Murphy (1992) and Card and Lemieux (2001). As for the elasticities $\sigma_{\mathrm{k}}$ we experiment with different values, in the vicinity of the estimates of Table 1. 
Table 3

Estimates of the "Own" Wage Elasticity to Flows of Immigrants within the Same Skill-Group

\begin{tabular}{|c|c|c|c|}
\hline & Source, Method and Sample & $\begin{array}{l}\text { Elasticity of US-born } \\
\text { wages to immigration } \\
\text { within the same skill } \\
\text { group, keeping output } \\
\text { constant }\end{array}$ & $\begin{array}{l}\text { Calculated elasticity } \\
\text { from table } 2 \\
\text { (range for the parameter } \\
\text { values in specification } 2 \\
\text { and } 3 \text { ) }\end{array}$ \\
\hline 1 & $\begin{array}{l}\text { Borjas, (2003), IV, national 1960- } \\
\text { 2000, Skills: } 32 \text { experience-education } \\
\text { groups }\end{array}$ & $\begin{array}{l}-0.29 * \\
(0.11)\end{array}$ & $\begin{array}{c}\overline{\gamma_{w k j}^{\text {own }}}= \\
-0.13 /-0.18\end{array}$ \\
\hline 2 & $\begin{array}{l}\text { Ottaviano and Peri, IV, national, 1970- } \\
2000,32 \text { experience-education groups }\end{array}$ & $\begin{array}{l}-0.15^{*} \\
(0.04)\end{array}$ & $\begin{array}{c}\gamma_{w k j}^{\text {own }}= \\
-0.13 /-0.18\end{array}$ \\
\hline 3 & $\begin{array}{l}\text { Card (2001), IV } 175 \text { MSA's 1985- } \\
\text { 1990. } 6 \text { Skill groups (occupation- } \\
\text { based) }\end{array}$ & $\begin{array}{l}-0.03 /-0.10^{*} \\
(0.02 / 0.04)\end{array}$ & n.a. \\
\hline 4 & $\begin{array}{l}\text { Borjas, (2003), IV, national 1960- } \\
\text { 2000, Skills: } 4 \text { education groups }\end{array}$ & $\begin{array}{l}-0.75^{*} \\
(0.64)\end{array}$ & $\begin{array}{l}\overline{\gamma_{w k}^{\text {own edu }}}= \\
-0.30 /-0.40\end{array}$ \\
\hline 5 & $\begin{array}{l}\text { Ottaviano and Peri, IV, } 86 \text { MSA's, } \\
\text { 1970-2000, } 4 \text { education groups. }\end{array}$ & $\begin{array}{l}-0.45^{*} \\
(0.25)\end{array}$ & $\begin{array}{l}\overline{\gamma_{w k}^{\text {own edu }}}= \\
-0.30 /-0.40\end{array}$ \\
\hline
\end{tabular}

Notes:

1. Estimate is taken from the estimate of Equation 16, page 1363 in Borjas (2003)

2. Our Estimates, adopting the same methods and variable choices as Borjas (2003). Only differences: hourly wages, rather than weekly, exclude 1960 from the sample and use IPUMS (rather than CPS) as data source for 2000.

3. Estimates of the effect on US-born employment are taken from Table 4 in Card (2001), only the IV estimates (specification E,F and G). Estimates of the effect on US-born wages are taken from table 7 in Card (2001) only IV estimates for US-born Males (specification $\mathrm{D}, \mathrm{E}, \mathrm{F}, \mathrm{G})$.

4. Estimate is taken from the estimate of Equation 17, page 1363 in Borjas (2003)

5. Our Estimates, using cross-city variation and instruments, based on Card (2001) described in the main text. 
Table 4

Estimates of the Total Effects of Immigration on Wages of US-Born Workers in Each Skill Group

\begin{tabular}{|c|c|c|c|}
\hline Specification: & $\mathbf{I}$ & II & III \\
\hline $\begin{array}{l}\text { Sample and Method of } \\
\text { Estimation: }\end{array}$ & $\begin{array}{l}\text { 1970-2000 } \\
\text { Panel IV } \\
86 \text { MSA }\end{array}$ & $\begin{array}{l}1970-1990 \\
\text { Panel IV } \\
117 \text { MSA }\end{array}$ & $\begin{array}{l}\text { Calculated elasticity } \\
\text { from Table } 2 \\
\text { (range for the } \\
\text { parameter values in } \\
\text { specification } 2 \text { and } 3 \text { ) }\end{array}$ \\
\hline $\begin{array}{l}\gamma_{w k j}^{\text {total }} \\
\text { (High school Dropouts) }\end{array}$ & $\begin{array}{l}-0.10 \\
(0.24)\end{array}$ & $\begin{array}{l}-0.20 \\
(0.17)\end{array}$ & -0.30 \\
\hline $\begin{array}{l}\gamma_{w k j}^{\text {total }} \\
\text { (High School Graduates) }\end{array}$ & $\begin{array}{l}0.15 \\
(0.19)\end{array}$ & $\begin{array}{l}0.20 \\
(0.15)\end{array}$ & $0.31-0.33$ \\
\hline $\begin{array}{l}\gamma_{w k j}^{\text {total }} \\
\text { (College Dropouts) }\end{array}$ & $\begin{array}{l}0.17 \\
(0.20)\end{array}$ & $\begin{array}{l}0.23 \\
(0.15)\end{array}$ & $0.28-0.31$ \\
\hline $\begin{array}{l}\gamma_{w k j}^{\text {total }} \\
\text { (College Graduates) }\end{array}$ & $\begin{array}{l}0.40^{*} \\
(0.20)\end{array}$ & $\begin{array}{l}0.40^{*} \\
(0.15)\end{array}$ & $0.31-0.44$ \\
\hline City Dummies & Yes & Yes & \\
\hline Year Dummies & Yes & Yes & \\
\hline Observations & 344 & 351 & \\
\hline
\end{tabular}

Note: The parameter estimates in each cell of Column I and II are from a separate panel regression. We use as dependent variable $\Delta \ln (\mathrm{w})_{\mathrm{ckt}}$, the percentage change in average real (hourly) wage of US-born workers of education group $\mathrm{k}$ in city c for decade t. The average logarithmic wage for an education-group in a city in a census year is calculated as the city-specific intercept of a Mincerian regression of individual (log)wages on experience dummies, gender, race and marital status dummies restricting the sample to US-born individuals and running the regression separately for each education group and census year. In parentheses are Heteroskedasticity-robust standard errors.

Column III reports the values of the elasticity $\gamma_{w k j}^{\text {total }}$ obtained from the calculations in Table 2, using the values of structural parameters in specification 2 and 3. 
Table 5

\section{Estimates of the Total Effects of Immigration on Average Wages, Housing Values and In/Outflows of US-Born Residents: US Metropolitan Areas}

\begin{tabular}{|c|c|c|}
\hline Specification: & $\mathbf{I}$ & II \\
\hline $\begin{array}{l}\text { Sample and Method of } \\
\text { Estimation: }\end{array}$ & $\begin{array}{l}1970-2000 \\
\text { Panel IV } \\
86 \text { MSA }\end{array}$ & $\begin{array}{l}1970-1990 \\
\text { Panel IV } \\
117 \text { MSA }\end{array}$ \\
\hline$\gamma_{\mathrm{E}}$ & $\begin{array}{l}0.87 \\
(0.80) \\
\end{array}$ & $\begin{array}{l}1.30 \\
(0.74) \\
\end{array}$ \\
\hline $\begin{array}{l}\gamma_{w} \\
\text { (real hourly wages) }\end{array}$ & $\begin{array}{l}0.46^{*} \\
(0.21)\end{array}$ & $\begin{array}{l}0.38^{*} \\
(0.19)\end{array}$ \\
\hline $\begin{array}{l}\gamma_{\mathrm{w}} \\
\text { (real yearly wages) }\end{array}$ & $\begin{array}{l}0.35^{*} \\
(0.19) \\
\end{array}$ & $\begin{array}{l}0.36^{*} \\
(0.22) \\
\end{array}$ \\
\hline $\begin{array}{l}\gamma_{r} \\
\text { (real gross rents) }\end{array}$ & $\begin{array}{l}1.25^{*} \\
(0.40)\end{array}$ & $\begin{array}{l}1.11^{*} \\
(0.30)\end{array}$ \\
\hline $\begin{array}{l}\gamma_{\mathrm{r}} \\
\text { (real value of the house) }\end{array}$ & $\begin{array}{l}1.61 * \\
(0.75) \\
\end{array}$ & $\begin{array}{l}1.60^{*} \\
(0.60) \\
\end{array}$ \\
\hline City Dummies & Yes & Yes \\
\hline Year Dummies & Yes & Yes \\
\hline Observations & 344 & 351 \\
\hline
\end{tabular}

The parameter estimate in each cell are from a separate panel regression. The explanatory variables in each regression are city dummies, time dummies and the increase in foreign-born workers as a percentage of initial total employment, as defined by $\Delta \mathrm{f}_{\mathrm{ct}}$ in the text. Method of estimation: Instrumental variables using the "constructed" inflow of immigrants (from initial shares by nationality and average immigration rates into the US, described in the text) as Instrument for $\Delta$ f.

Units of observation: Metropolitan Statistical Areas (MSA) consistently defined across Census years.

Heteroskedasticity-robust standard errors are reported in parenthesis.

$*=$ significant at $5 \%$ confidence level.

First Row, Estimates of $\gamma_{\mathrm{E}}$. The dependent variable is $\Delta \mathrm{n}_{\mathrm{ct}}$, the change in US-born workers in city (MSA) c during decade $t$ as percentage of the initial total employment. Specification I uses a sample of 86 MSA's for the 1970-2000 period, specification II uses 117 MSA's for the 1970-1990 period.

Second and Third Row, Estimates of $\gamma_{w}$. The dependent variable is $\Delta \ln (w)_{c t}$, the percentage change in average real wage (hourly in the second and yearly in the third row) of US-born workers in city c for decade t. The average logarithmic wage for a city in a census year is calculated as the city-specific intercept of a mincerian regression of individual (log)wages on education dummies, experience dummies, gender, race and marital status dummies restricting the sample to US-born individuals and running the regression separately for each census year.

Fourth and Fifth Row, Estimates of $\gamma_{\mathrm{r}}$. The dependent variable is $\Delta \ln (\mathrm{r})_{\mathrm{ct}}$, the percentage change in average real monthly rent (fourth row) or house value (fifth row) divided by the number of rooms, for US-born individuals in city $\mathrm{c}$ for decade $\mathrm{t}$. 
Table 6

Simulation of the Long-Run Impact of Immigration Shock on Wages, Housing Values and In/Outflows of US-born residents, from the City-Model

\begin{tabular}{|c|c|c|c|c|c|c|c|}
\hline & (I) & (II) & (III) & (IV) & $(\mathrm{V})$ & $(\mathrm{VI})$ & (VII) \\
\hline \multicolumn{8}{|c|}{ Immigration Shock : $\Delta \mathrm{f}=8 \%, \Delta \mathrm{f}_{\mathrm{HSD}}=1.9 \%, \Delta \mathrm{f}_{\mathrm{HSG}}=1.5 \%, \Delta \mathrm{f}_{\mathrm{COD}}=1.5 \% . \%, \Delta \mathrm{f}_{\mathrm{COg}}=3.0 \%$} \\
\hline \multicolumn{8}{|c|}{ Parameter Values } \\
\hline $1-\alpha-\beta$ & 0.2 & 0.2 & 0.2 & 0.2 & 0.25 & 0.2 & 0.2 \\
\hline $\mathrm{B}$ & 0.2 & 0.2 & 0.2 & 0.2 & 0.2 & 0.15 & 0.2 \\
\hline$\gamma$ & 6 & 6 & 6 & 7 & 6 & 6 & 6 \\
\hline$\delta$ & 1.8 & 1.8 & 1.8 & 1.8 & 1.8 & 1.8 & 2 \\
\hline$\sigma_{\mathrm{HSD}}$ & 6 & 7 & 20 & 6 & 6 & 6 & 6 \\
\hline$\sigma_{\mathrm{HSG}}$ & 7 & 10 & 20 & 7 & 7 & 7 & 7 \\
\hline$\sigma_{\mathrm{COD}}$ & 7 & 10 & 20 & 7 & 7 & 7 & 7 \\
\hline$\sigma_{\mathrm{COG}}$ & 3 & 4 & 20 & 3 & 3 & 3 & 3 \\
\hline \multicolumn{8}{|c|}{ Short-Run (Impact) Effect } \\
\hline $\begin{array}{l}\text { Change of average Wage } \\
\text { US born }\end{array}$ & $2.8 \%$ & $2.0 \%$ & $0.5 \%$ & $2.8 \%$ & $2.8 \%$ & $2.8 \%$ & $2.7 \%$ \\
\hline $\begin{array}{l}\text { Change of average Value of } \\
\text { Houses }\end{array}$ & $10.2 \%$ & $9.3 \%$ & $7.9 \%$ & $10.2 \%$ & $10.2 \%$ & $10.2 \%$ & $10 \%$ \\
\hline \multicolumn{8}{|c|}{ Long-Run Effect } \\
\hline $\begin{array}{l}\text { Change of average Wage } \\
\text { US born }\end{array}$ & $3.4 \%$ & $2.9 \%$ & $1.5 \%$ & $3.5 \%$ & $3.6 \%$ & $3.6 \%$ & $3.3 \%$ \\
\hline $\begin{array}{l}\text { Change of average Value } \\
\text { of Houses }\end{array}$ & $12.9 \%$ & $9.7 \%$ & $4.2 \%$ & $12.6 \%$ & $10.7 \%$ & $10.7 \%$ & $13 \%$ \\
\hline Total Migration of US born & $2.3 \%$ & $-0.3 \%$ & $-4.9 \%$ & $2.0 \%$ & $-0.1 \%$ & $-0.1 \%$ & $2.6 \%$ \\
\hline \multicolumn{8}{|c|}{ Implied Long-Run Elasticities } \\
\hline$\gamma_{\mathrm{w}}$ & 0.42 & 0.35 & 0.19 & 0.42 & 0.44 & 0.44 & 0.40 \\
\hline$\gamma_{\mathrm{r}}$ & 1.58 & 1.18 & 0.52 & 1.55 & 1.31 & 1.32 & 1.59 \\
\hline$\gamma_{\mathrm{E}}$ & 0.28 & -0.06 & -0.61 & 0.24 & -0.02 & -0.01 & 0.31 \\
\hline
\end{tabular}

The Value of all other parameters as well as the initial conditions in the supply of US-born and Foreign-born workers of each skill group are constant across simulations and are reported in the section "Simulation of the Model" in the text. The simulated shock equals in magnitude and skill composition the inflow of foreign-born workers in the period 1990-2000. 